\title{
ESPAÑA Y LA UE: \\ OBJETIVO IDEOLÓGICO \\ Y PROYECTO POLÍTICO \\ (1978-2018)
}

ANTONIO BAR CENDÓN 
1. INTRODUCCIÓN. 2. EUROPA COMO OBJETIVO IDEOLÓGICO. 3. EUROPA COMO PROYECTO POLÍTICO. A) El primer paso: el Acta Única Europea. B) La ciudadanía y la cohesión: el Tratado de Maastricht. C) El papel exterior y la política social: el Tratado de Ámsterdam. D) El refuerzo de la posición institucional: el Tratado de Niza. E) De la firmeza a la cesión: la Constitución europea. F) Debilidad y reubicación: el Tratado de Lisboa. 4. CONCLUSIONES 


\title{
ESPAÑA Y LA UE: OBJETIVO IDEOLÓGICO Y PROYECTO POLÍTICO (1978-2018)
}

\author{
ANTONIO BAR CENDÓN ${ }^{1}$ \\ Catedrático de Derecho Constitucional \\ Catedrático Jean Monnet «ad personam» \\ Universidad de Valencia
}

\section{INTRODUCCIÓN}

El ingreso de España en las Comunidades Europeas, primero, y en la Unión Europea, después, ha resultado ser extraordinariamente beneficioso para el país. Es verdad que, en un primer momento, algunos sectores de la estructura económica española se vieron seriamente afectados, sin embargo, el resultado final de todo el proceso ha sido muy positivo. Efectivamente, desde su ingreso en las Comunidades Europeas (en adelante CCEE) el 1 de enero de 1986, ${ }^{2}$ España ha experimentado un rápido y notable proceso de crecimiento económico, de modernización y de apertura al exterior que no tiene parangón en los procesos de adhesión a las CCEE, o a la Unión Europea (en adelante UE), que se han realizado desde su surgimiento, desde el punto de vista del pleno y eficaz aprovechamiento de los recursos y de los medios puestos a su disposición por las CCEE.

En este sentido, España supo aprovechar y utilizar muy bien las compensaciones económicas recibidas de las CCEE, principalmente a través de los fondos estructurales —el Fondo Europeo de Desarrollo Regional, el Fondo Social Europeo y el Fondo

${ }^{1}$ Catedrático de Derecho Constitucional. Catedrático Jean Monnet «ad personam». Departamento de Derecho Constitucional y Ciencia Política y de la Administración. Facultad de Derecho. Universidad de Valencia. Avda. dels Terongers, s/n. 46022 Valencia. Email: antonio.bar@uv.es

${ }^{2}$ El Tratado de Adhesión a las Comunidades Europeas se firmó el 12 de junio de 1985 y entró en vigor el 1 de enero de 1986. Vid. Tratado [...] Relativo a la adhesión del Reino de España y de la República Portuguesa a la Comunidad Económica Europea y a la Comunidad Europea de la Energía Atómica (DO L 302, 15.11.1985). Instrumento de ratificación por España de 20.9.1985 (BOE n. 1, 1.1.1986, pp. 3-687). 
de Cohesión-, que sirvieron para compensar tanto las pérdidas y las renuncias que hubo de hacer en varios ámbitos relevantes de su estructura económica - la pesca, la agricultura, la ganadería, la siderometalurgia, la construcción naval—, como los esfuerzos de adaptación que hubo de realizar en otros sectores económicos y políticos. Compensaciones que, en todo caso, permitieron reequilibrar y modernizar la economía española, fundamentalmente a través de la mejora de sus infraestructuras. Pero España ha sabido también aprovechar al máximo el nuevo posicionamiento que el ingreso en las CCEE le atribuía, tanto en su relación con los nuevos socios europeos, como en el conjunto de las relaciones internacionales. En este sentido, puede afirmarse que el beneficio obtenido por España de las CCEE se deriva no sólo de las compensaciones económicas recibidas, sino también de la eficaz posición negociadora de los gobiernos españoles en el seno de las mismas, y también, desde luego, del compromiso activo de España con el proyecto de construcción europeo. Compromiso manifestado de manera permanente a lo largo de todo este período histórico, y en términos similares, por los cuatro presidentes del Gobierno que ha tenido España desde su ingreso en las CCEE, pertenecientes a diferentes formaciones políticas: Felipe González, José María Aznar, José Luis Rodríguez Zapatero y Mariano Rajoy.

En realidad, desde muy pronto, España hizo del proceso de integración europeo un objetivo ideológico y un proyecto político. Un objetivo ideológico que ha sido — que es aún hoy - compartido por la práctica totalidad de los partidos políticos mayoritarios. Y un proyecto político cuya realización — que sigue en curso — afecta no sólo al propio gobierno de la UE, sino también a la estructura y al modo del gobierno de España. Y, en verdad, el ingreso de España en las CCEE, en enero de 1986, supuso la realización de ese objetivo ideológico y de ese proyecto político. Claro es, esa realización no podía ser perfecta. No podía serlo, en la medida en la que, por propia definición, los proyectos ideológicos son sólo interpretaciones particulares de la realidad y sus realizaciones prácticas nunca son completas. En este sentido, la culminación del objetivo de entrar en las CCEE supuso sólo el inicio de un camino, en cuyo desarrollo las fuerzas políticas españolas experimentaron — lo hacen aún hoy en día- sentimientos encontrados de satisfacción y de frustración, y esto ha dependido, y depende, de los planteamientos propios de cada partido, pero también de las actuaciones de las CCEE y de la UE en cada caso. Así — como ya se ha dicho_España ha experimentado cambios e innovaciones que han resultado ser muy positivos; pero también ha tenido que ceder una parte sustantiva de su soberanía y ha tenido que realizar importantes modificaciones en su ordenamiento jurídico, en la Constitución y en la legislación ordinaria.

Estos cambios experimentados por España en todos los ámbitos —económico, político, social — han sido descritos y analizados ya, con todo detalle y extensión, por la doctrina científica propia de cada campo. En este trabajo, en un sentido inverso, lo que se trata de analizar no es lo que las CCEE y la UE han aportado a España, sino más bien lo que España ha aportado a ese proceso europeo de integración y a su desarrollo en cada fase del mismo, a partir de 1986. Y este análisis se hace partiendo 
precisamente de lo que fueron los planteamientos políticos e ideológicos de las principales fuerzas políticas del momento, las cuales, en términos generales, apoyaron el ingreso de España y el desarrollo de este proceso de integración; aspecto al que se dedica el apartado 2 del trabajo. A lo que sigue inmediatamente un análisis detallado de lo que han sido las aportaciones más relevantes de la contribución española a la realización de ese proceso de integración, en cada fase del mismo; aspecto al que se dedica el apartado 3 del trabajo. En el primer caso, el análisis se basa en una selección de los documentos más significativos adoptados por los partidos políticos mayoritarios y más implicados en este proceso. Y, en el segundo caso, el análisis se basa en el proceso de formulación y ratificación de los tratados que la UE ha aprobado desde el ingreso de España, en 1986.

Se trata, en definitiva, de estudiar una dimensión de la integración de España en las CEE y en la UE que, hasta el presente, no ha sido tratada con el interés y la extensión que merece el tema.

\section{EUROPA COMO OBJETIVO IDEOLÓGICO}

La inclusión en el proceso de integración económica y política que se inicia en Europa con la creación de las CCEE, en los años cincuenta del siglo pasado, es un objetivo común de prácticamente todas las fuerzas políticas españolas desde aquel mismo momento, incluidos los sectores más cercanos al régimen franquista. No puede olvidarse, en este último sentido, que España presentó muy pronto su primera solicitud de adhesión a las CCEE, en 1962, bajo el régimen del General Franco y sólo cuatro años después de la entrada en funcionamiento de la Comunidad Económica Europea. ${ }^{3}$ Y este objetivo común es aún hoy compartido por la práctica totalidad de los partidos políticos mayoritarios, de izquierda a derecha, y tanto entre los partidos de ámbito nacional como entre los partidos nacionalistas regionales.

Es verdad, sin embargo, que la aproximación a ese proceso de integración europeo, y la percepción del mismo, era diferente. En el lado del Gobierno, tras el fallecimiento del General Franco, el 20 de noviembre de 1975, continuando con la línea oficial mantenida desde los años sesenta, el Presidente Arias Navarro ordenó al nuevo Ministro de Asuntos Exteriores, José M. ${ }^{a}$ de Areilza, reiniciar los contactos con Bruselas, con la mera intención inicial de reactivar y actualizar el viejo Acuerdo Comer-

3 España fue el tercer Estado europeo en solicitar su adhesión a las CCEE, tras Turquía, que presentó su solicitud de ingreso en 1959, y el Reino Unido, Dinamarca, Irlanda y Noruega, que presentaron simultáneamente su primera solicitud de adhesión a las CCEE en mayo de 1960. La solicitud española fue presentada el 9 de febrero de 1962 por el entonces Ministro de Asuntos Exteriores del Gobierno del General Franco, Fernando M. ${ }^{a}$ Castiella. España, sin embargo, sólo recibió entonces un mero acuse de recibo de su solicitud. España tendría que esperar hasta 1970 para obtener de las CCEE simplemente un Acuerdo Comercial Preferencial (Luxemburgo, 29 de junio de 1970); acuerdo que se completó con un Protocolo adicional el 29 de enero de 1973. 
cial Preferencial. ${ }^{4}$ Sin embargo, los verdaderos contactos con Bruselas tendentes al acceso de España a las CCEE no se iniciarían sino tras las elecciones de 15 de junio de 1977 y la formación del segundo Gobierno de Adolfo Suárez. Es entonces cuando, el 28 de julio de 1977, el nuevo Ministro de Asuntos Exteriores, Marcelino Oreja, presenta formalmente la solicitud de adhesión de España a las CCEE. La visión del Gobierno y de su partido, sin embargo, se perfilarán mejor con la constitución formal de la Unión de Centro Democrático (UCD) en 1978. El partido se define entonces como «el partido político organizado a nivel de toda España con más clara vocación europeísta; en otras palabras, es el que más profundamente se identifica con la organización política y socio-económica de Europa occidental, que no es «marxista-revolucionaria» ni defiende los intereses de una derecha política y económica con claras herencias autoritarias». La UCD dice defender entonces la «unión política de la Europa occidental», una Europa «unida y democrática», y el modelo de una «Europa progresista dentro del mundo occidental».

Por su parte, el partido heredero del régimen franquista, Alianza Popular (AP), fundada en octubre de 1976 por varios ex-ministros del Gobierno del General Franco, mantuvo, aún varios años después de la desaparición del régimen —y ya desde la oposición-, la postura sostenida por el Gobierno transitorio de Arias Navarro, en el sentido de que se debía mantener el Acuerdo Preferencial de 1970 hasta la plena integración de España en las CCEE, dado que ello «podría facilitar las negociaciones para el ingreso al resolver dificultades importantes que se presentaban en las relaciones comerciales». En todo caso, para AP, el ingreso de España en las CCEE era un objetivo a alcanzar, considerándolo como «la referencia estratégica clave para la empresa, la economía y la sociedad» españolas. «Nuestro país — decía AP— es y se siente europeo y nada de lo que ocurra en Europa es ajeno a nosotros, no pudiendo ser meros espectadores en la construcción de Europa». En esta línea «[p]ara España, y más concreto para las empresas industriales españolas, la adhesión a las Comunidades debe significar una posibilidad y un acicate para la modernización [...] Necesitamos pues una Europa de la 2a Generación, con importantes políticas económicas, una Europa poderosa económicamente que puede asumir un nuevo miembro sin graves contratiempos económicos». ${ }^{6}$

En la izquierda, los partidos más poderosos entonces eran el Partido Comunista de España (PCE) y el Partido Socialista Obrero Español (PSOE). Ambos partidos se manifestaron al inicio como anticapitalistas, contrarios, no a la integración europea, pero sí al proceso de integración tal y como ellos entendían que se estaba

${ }^{4}$ El Consejo había decidido suspender todos los contactos con España, tras los últimos fusilamientos de dos miembros de ETA y tres del FRAP, el 27 de septiembre de 1975.

5 Unión de Centro Democrático (UCD). Primer Congreso Nacional, Principios ideológicos y modelo de sociedad de UCD (Madrid, 19-23 de octubre de 1978). En: http://e-spacio.uned.es/fez/eserv.php?pi$\mathrm{d}=$ bibliuned:DerechoPolitico-1978-1979-2-13210\&dsID=PDF

6 Alianza Popular, VI Congreso Nacional de Alianza Popular. Barcelona, 27, 28 y 29 de enero de 1984. Punto 4.‥ España-CEE. 
produciendo entonces; contrarios a una Europa que consideraban como la «Europa de los mercaderes», la «Europa del gran capital». Y, en la misma línea, se manifestaban igualmente contrarios al ingreso de España en la OTAN, por entender que ello perjudicaba al interés y a la seguridad de España y alteraba el equilibrio existente entre los dos grandes bloques en conflicto. Así, para el PCE, Europa debía ser una continuación lógica del ámbito nacional de su lucha política. «El PCE — decía en 1975- considera su propia lucha como parte de las luchas de las fuerzas obreras y democráticas en Europa por dar una salida positiva a la crisis económica, reducir y destruir el poder de los monopolios, defender y desarrollar las libertades, abrir una vía democrática al avance hacia el socialismo». La visión de Europa, pues, se encajaba dentro de su visión revolucionaria de la política y la sociedad en el ámbito español; en este sentido, decía: «los monopolios dirigen el Mercado Común, y lo aprovechan en su beneficio. Hace falta lograr, por la lucha de las masas en cada país, por su mayor coordinación a nivel europeo, que la clase obrera, las fuerzas progresistas, transformen en un sentido democrático el carácter de la Comunidad Económica Europea»; y, en fin, añadía: «A la Europa de los monopolios oponemos la Europa de los pueblos». ${ }^{7}$

Este planteamiento radical, sin embargo, se suavizó un poco más tarde y, de hecho, la flexibilización y el pragmatismo de la actuación política del PCE fueron decisivos en la transición a la democracia y la consolidación del nuevo régimen político salido de la Constitución de 1978. Así, ya en 1983, cuando España se encontraba inmersa en el proceso negociador para la adhesión a las CCEE, de la mano del Gobierno de Felipe González, el PCE se pronuncia claramente a favor de la integración de España en las CCEE y lo hace en términos más suaves. España — dice el PCE entonces - «debe asumir plenamente su condición de país europeo, haciendo suyas las mejores tradiciones políticas y culturales de Europa, aquéllas por las que la clase obrera ha luchado desde su misma aparición: las libertades, la democracia, el pluralismo político, la tolerancia de los derechos humanos, el carácter laico del Estado, la soberanía popular y la supremacía del poder civil». Y añade: «Esta es la Europa que queremos contribuir a potenciar y en la que queremos integrarnos. La Europa de los pueblos y de la paz. No la de los monopolios y el atlantismo». Ello, sin embargo, no evita la dura crítica del PCE a las posiciones negociadoras con las CCEE mantenidas entonces por el Gobierno socialista de González. El PCE se manifiesta «partidario de un examen riguroso de los contenidos y ritmos de la negociación» y «reclama un amplio debate político sobre la integración de España en la CEE. [...] Un debate que debe permitir crear un clima de unidad de las fuerzas sociales y políticas del país necesario para hacer frente a las pretensiones comunitarias, y que asimismo determine las condiciones y el momento apropiado para la entrada de España en la CEE». El PCE, en fin, «sigue empeñado en contribuir al ingreso de España en el [mercado

7 Partido Comunista de España, Manifiesto Programa del PCE. Aprobado en la II Conferencia del PCE (Septiembre 1975). Punto 15: Necesidad de una coordinación de la lucha de clases en la Europa capitalista. 
común] en las condiciones más favorables posibles para nuestro país [...]. Estamos convencidos que, a plazo medio y largo, ello es de interés mutuo para España y para la transformación democrática y progresista de la CEE». A lo que se añade: «Y pensamos también que la crisis económica que conoce hoy nuestro país no tiene solución progresista en una estrategia de aislamiento. Es más, esta no supondría sino una mayor satelización económica, política y militar de nuestro país respecto de los Estados Unidos de América». ${ }^{8}$

El PSOE tiene también, inicialmente, una aproximación a Europa condicionada por un planteamiento ideológico radical y revolucionario. El PSOE se declaraba en 1977 «Partido de Clase, y, por lo tanto, de masas, marxista y democrático». Un partido «internacionalista y antiimperialista» y también «autogestionario». En este contexto, el PSOE entendía, sin embargo, que «España está abocada a Europa en cuya área geográfica se enclava», si bien, al mismo tiempo, denunciaba ante las instituciones europeas el proceso de reforma política que entonces iniciaba el primer Gobierno Suárez, antes de las elecciones de junio de 1977, «instando a los partidos hermanos y a los gobiernos democráticos a que continúen oponiéndose al ingreso de España en los organismos e instancias europeas mientras persista su naturaleza [no] democrática y hasta la instauración plena de la democracia en nuestro país». ${ }^{9}$ Esta radical posición ideológica se modera sustantivamente en el Congreso extraordinario del partido, de septiembre de 1979, en el que se abandona la definición del PSOE como partido marxista y se asume el marxismo simplemente «como un instrumento teórico, crítico y no dogmático, para el análisis y la transformación de la realidad social». ${ }^{10} \mathrm{La}$ política internacional del PSOE estuvo, sin embargo, dominada aún unos años más por una visión neutralista, contraria a la política de bloques —a la OTAN-y más cercana a los planteamientos de los países no alineados que a la visión de las CCEE. La desintegración progresiva de la UCD y la percepción de la cercanía del momento de asumir el gobierno de España, hicieron al PSOE cambiar su perspectiva. Así, ya en 1981 el PSOE defendía la opción europea como «una opción fundamentalmente política de incorporación a la construcción de una Europa unida democrática, pluralista y progresista», si bien insistía aún en la necesidad de la «consecución de una sociedad europea inspirada en el socialismo democrático de los pueblos y los trabajadores, poniendo cota a la expansión del capital multinacional, y al intervencionismo norteamericano». ${ }^{11}$

${ }^{8}$ Partido Comunista de España, XI Congreso del Partido Comunista de España (Diciembre 1983). Una política exterior de paz y neutralidad.

9 PSOE, XXVII Congreso del Partido Socialista Obrero Español (Madrid 4, 5, 6 y 7 de Noviembre de 1976). Resolución Política. Publicado en Nueva Sociedad, n. 28 (Enero-Febrero, 1977).

10 PSOE, Congreso Extraordinario, Madrid, 28-29 de septiembre de 1979. Resolución política del Congreso Extraordinario. En: http://www.psoe.es/media-content/2016/04/resoluciones-197909-congreso-extraordinario.pdf

11 PSOE, 29 Congreso. Anexo del Acta del 29 Congreso. Resoluciones. Madrid, 21-24 de Octubre de 1981. En: http://www.psoe.es/media-content/2016/04/resoluciones-198110-29congreso2.pdf 
Es, efectivamente, la llegada al Gobierno en diciembre de 1982 y la asunción de la dirección de las negociaciones de adhesión con las CCEE — que padecían entonces un estancamiento debido a las malas relaciones entre Suárez y Giscard d'Estaing, la cuestión agrícola y el terrorismo de ETA—, lo que va a hacer cambiar de perspectiva al PSOE. En este sentido, en el último congreso del partido de 1984, antes de la entrada de España en las CCEE, el PSOE proponía una política exterior «realista», basada en el propio perfil de España, su «situación geográfica, trayectoria histórica, grado de desarrollo socioeconómico y sistema político del que los españoles nos hemos dotado». Así, decía el PSOE, «[e]stas características nos sitúan dentro del mundo de las democracias occidentales europeas y nos hacen, en consecuencia, coparticipes de sus valores y también de los problemas y retos con los que se enfrentan». Para el PSOE —en, quizá, la más elaborada y certera de sus posiciones programáticas sobre Europa- la identidad primordial del partido es «europea»: "Afirmamos nuestra identidad europea y, consecuentemente, nuestra vocación de participar activamente en la tarea histórica de la construcción de Europa». A lo que se añade inmediatamente: «Para el PSOE, se trata de una opción política integral: hacia dentro, porque queremos vincular definitivamente España al conjunto de las democracias europeas e impulsar la labor de modernización social y económica que nos equipare a ella. Hacia fuera, porque aspiramos a contribuir a la formación de una Europa unida y fuerte, capaz de asumir su propio destino y de responder a los retos que se plantean a los europeos en todos los planos». ${ }^{12}$ Es precisamente en este nuevo contexto en el que, de la mano del Gobierno socialista de Felipe González, se van a encuadrar decisiones tan importantes como la conclusión de las negociaciones con las CCEE y la firma del Tratado de Adhesión, en junio de 1985, y la convocatoria del referéndum para la permanencia de España en la OTAN, que se celebró el 12 de marzo de 1986, sólo tres meses después del ingreso efectivo de España en las CCEE.

En lo que se refiere a los partidos nacionalistas regionales, tanto los vascos, como los catalanes y los gallegos, fueron siempre favorables al proceso de integración europeo. Los nacionalistas gallegos, sin embargo, sobre todo en sus sectores más radicales e izquierdistas, se desprendieron de su europeísmo para adoptar posiciones muy críticas con respecto al proceso europeo, tras la entrada de España en las CCEE, en la medida en que vieron como la integración económica afectaba sustantivamente a los sectores más relevantes de la economía gallega: la pesca, la agricultura, la ganadería y la construcción naval. En términos generales, los partidos nacionalistas regionales han querido ver en Europa una salida a sus pretensiones de realización política, en el marco de lo que sería la construcción de la «Europa de los pueblos». Sin embargo, esta pretensión tiene un muy difícil encaje en un proyecto político — el europeo- que basa su identidad precisamente en la superación

${ }_{12}$ Partido Socialista Obrero Español. 30 Congreso, Madrid, 13-16 de diciembre de 1984. Anexo del Acta del 30 Congreso. Resoluciones. VI. Política Internacional. El fortalecimiento del papel de España en el mundo. En: http://www.psoe.es/media-content/2016/04/resoluciones-198412-30congreso.pdf 
de las fronteras nacionales y de los nacionalismos identitarios, que están en el germen del desastre de la Segunda Guerra Mundial. En este sentido, quizá las formulaciones políticas más elaboradas en este terreno y, por tanto, definidoras del conjunto, sean las del Partido Nacionalista Vasco. Este partido declaraba en 1977 —en pleno proceso de transición a la democracia - su «vocación europea, afirmada ya públicamente en el Aberri-Eguna de 1934 con el lema Euzkadi-Europa». Una vocación europea que suponía la creación de «una Europa de pueblos libres, con una base común de civilización y de cultura, libre en su ser político y diferencial y unidos bajo un techo estructural común político y económico, susceptible de cubrir un desarrollo comunitario, y no exclusivamente como una unión de los Estados actuales». En definitiva, «[e]n el marco de esta Europa de los pueblos es donde hallará su realización la unidad política de los vascos y su libertad, en igualdad y solidaridad con los demás pueblos europeos y con una estructura política propia surgida de la voluntad de todos los vascos». ${ }^{13}$

En este sentido, ya en 1982, en la etapa previa al ingreso en las CCEE, el Partido Nacionalista Vasco afirmaba que «asumía el deber de colaborar en la construcción y desarrollo de una Europa formada por pueblos libres en su ser político y diferencial, liberada de los condicionamientos y dependencias de las políticas de bloques, democrática, progresiva y con vocación mundial, principios en los que se ratifica». ${ }^{14} \mathrm{Y}$, en similar sentido, si bien con una visión más práctica, menos ideologizada, Convergencia i Unió, la coalición de partidos de centro-derecha que gobernó Cataluña de manera prácticamente continuada durante casi cuarenta años, decía en 1984 que «[p]or razones históricas, sociales, políticas y también económicas, defendemos nuestra integración a las Comunidades Europeas», proponiendo al mismo tiempo un estrecho «seguimiento de las negociaciones para la adhesión, dándose el apoyo correspondiente para llegar a la total integración», la defensa de que «Catalunya sea definida como una «región europea» en la división territorial que a efectos de la política regional comunitaria debe presentar a las Comunidades Europeas el Gobierno español», y la defensa de que Catalunya sea una «circunscripción electoral para las elecciones al Parlamento Europeo». ${ }^{15}$

La integración económica y política de Europa, pues, más que un objetivo común, compartido por la práctica totalidad de los parridos políticos españoles, fue verdaderamente una identificación ideológica — «europeísta»— con la que éstos han querido distinguirse, desde el primer momento. Y esa identificación ha sido asumida tanto por los partidos inicialmente más cercanos al régimen franquista, como por los partidos democráticos que lucharon contra aquél. Eso, sin embargo, no ha impedido — como se ha visto- que la interpretación del euro-

13 PNV, Politika buruz jokabidea. Planteamiento politico. Documentos de la Asamblea Nacional, Iruña, 27 marzo 1977.

${ }_{14}^{14}$ PNV, Programa Electoral Partido Nacionalista Vasco - 1982. La integración del Estado en Europa.

15 Convergencia i Unió, Programa Electoral de Convergencia i Unió-1984. Capitulo XIV: Catalunya y la integración en la Comunidad Europea. 
peísmo, del proceso europeo de integración, haya sido — sea- diferente de partido a partido, o que, incluso, haya evolucionado bastante en el seno de un mismo partido, como ha sido, por ejemplo, el caso del PSOE, y de manera muy notoria. En todo caso — como ya se dijo en la introducción-, la realización de ese objetivo ideológico y de ese proyecto político que supuso el ingreso de España en las CCEE y en la UE, no fue perfecta ni satisfizo plenamente a todos, ni de manera igual en todas y cada una de las fases del proceso. Sin embargo, es digno de ser subrayado aquí el hecho de que ninguno de los partidos mencionados opuso nunca traba sustantiva alguna, o veto, a la labor negociadora con las CCEE, o a la labor de gobierno referida a la relación de España con aquéllas, por parte del Gobierno en ejercicio, fuese éste del PSOE o del PP. Más bien al contrario, en términos generales y no sin duras críticas en más de una ocasión, los gobiernos en ejercicio han solido tener el respaldo de los partidos de la oposición en todos los momentos clave de este proceso. Europa, pues, ha operado como un factor ideológico de identificación de las fuerzas políticas españolas y, en última estancia, también como un factor de colaboración entre ellas.

\section{EUROPA COMO PROYECTO POLÍTICO}

El proyecto político europeo se ha ido articulando, desde los años cincuenta del siglo pasado, a través de una secuencia de tratados internacionales que han ido conformando, primero, las Comunidades Europeas, y luego lo que es hoy en día la Unión Europea. España, como es evidente, no participó en el proceso fundacional de las CCEE, pero sí lo hizo, y de manera muy activa, en el proceso de integración política que, a partir del año 1986, lleva a la creación de la UE, como una entidad supranacional. Una entidad supranacional cuyo contenido político debe muchos de sus aspectos precisamente a la labor de España en su seno.

Así, desde el año 1986, las CCEE y la UE han aprobado seis tratados generales de reforma de los Tratados constitutivos y una Decisión del Consejo Europeo de reforma de un artículo específico —el Art. 136 — del Tratado de Funcionamiento de la Unión Europea, la cual, si bien no es —en términos propios- un tratado de reforma, sí tiene la misma eficacia y valor jurídico. A ellos han de ser añadidos dos nuevos Protocolos, concluidos al margen de los mencionados tratados de reforma, y que hoy acompañan a los Tratados constitutivos. Y, finalmente, algunos de los Estados miembros de la UE han concluido entre sí, además, cuatro tratados internacionales, claramente referidos al contenido sustantivo y a la dinámica interna de la UE, los cuales, sin embargo, por motivos diversos, han tenido que ser concluidos al margen del ordenamiento jurídico de la UE y, por lo tanto, desde un punto de vista estrictamente formal, no son parte del ordenamiento jurídico de la Unión. No obstante, parte del contenido material de estos tratados ha terminado por ser integrado más tarde en el articulado de los Tratados constitutivos de la UE. 
A todo ello, en fin, debe ser añadida la Carta de los Derechos Fundamentales de la Unión Europea, que fue proclamada inicialmente en Niza, el 7 de diciembre de 2000, por los Presidentes del Parlamento Europeo, del Consejo y de la Comisión. ${ }^{16}$ La Carta sería incluida luego como Parte II del Tratado por el que se establece una Constitución para Europa, en 2004, y, por lo tanto, feneció con él. Ello hizo que, tras concluirse el Tratado de Lisboa, la Carta tuviese que ser proclamada de nuevo, lo que hicieron, una vez más, los Presidentes del Parlamento Europeo, del Consejo y de la Comisión, en Estrasburgo, el 12 de diciembre de 2007. La Carta no es, en términos propios, un tratado de la Unión, ni siquiera un Protocolo de los que les acompañan; no es, en este sentido, un acuerdo internacional concluido por los gobiernos de los Estados miembros de la UE. La Carta es, en realidad, un documento que se deriva de las propias instituciones de la Unión, que son quienes lo han proclamado formalmente; sin embargo, su valor jurídico es el mismo que el de los Tratados, tal y como lo establece el Art 6.1 del Tratado de la Unión Europea. La Carta, pues, forma parte de la estructura constitucional de la UE, junto con el Tratado de la Unión Europea (en adelante TUE) y el Tratado de Funcionamiento de la Unión Europea (en adelante TFUE).

Los tratados de reforma de los Tratados constitutivos aprobados a partir de 1986 son: el Acta Única Europea (Luxemburgo, 17.2.1986; entró en vigor el 1.7.1987); el Tratado de la Unión Europea (Tratado de Maastricht, de 7.2.1992; entró en vigor el 1.11.1993); el Tratado de Ámsterdam (de 2.10.1997; entró en vigor el 1.5.1999); el Tratado de Niza (de 26.2.2001; entró en vigor el 1.2.2003); el Tratado por el que se establece una Constitución para Europa (Roma, 29.10.2004; no llegó a entrar en vigor); el Tratado de Lisboa (de 13.12.2007; entró en vigor el 1.12.2009); y la Decisión del Consejo Europeo de 25.3.2011, que modifica el Art. 136 TFUE en relación con un Mecanismo de Estabilidad para los Estados miembros cuya moneda es el euro (Bruselas, 25.3.2011; entró en vigor el 1.5.2013). Los nuevos Protocolos añadidos a los Tratados constitutivos son: el Protocolo por el que se modifica el Protocolo sobre las disposiciones transitorias, anejo al Tratado de la Unión Europea, al Tratado de Funcionamiento de la Unión Europea y al Tratado Constitutivo de la Comunidad Europea de la Energía Atómica (Bruselas, 23.6.2010; entró en vigor el 1.12.2011); y el Protocolo sobre las preocupaciones del pueblo irlandés con respecto al Tratado de Lisboa (Bruselas, 13.6.2012; entró en vigor el 1.12.14). (DO L 60, 2.3.2013).

Los tratados internacionales — «intergubernamentales»— referidos al contenido sustantivo y a la dinámica interna de la UE, pero concluidos por los Estados firmantes al margen del ordenamiento jurídico de la UE son: el Convenio de aplicación del Acuerdo de Schengen de 14 de junio de 1985 entre los Gobiernos de los Estados de la Unión Económica Benelux, de la República Federal de Ale-

${ }^{16}$ Carta de los Derechos Fundamentales de la Unión Europea (2000/C 364/01). (DO C 364, 18.12.2000). 
mania y de la República Francesa relativo a la supresión gradual de los controles en las fronteras comunes (Schengen, Luxemburgo, 19.6.1990; entró en vigor el 1.3.1994); el Convenio relativo a la profundización de la cooperación transfronteriza, en particular en materia de lucha contra el terrorismo, la delincuencia transfronteriza y la migración ilegal (más conocido como «Tratado de Prüm», por el nombre de la ciudad alemana donde fue concluido, el 27.5.2005; entró en vigor el 1.11.2006); el Tratado Constitutivo del Mecanismo Europeo de Estabilidad (Bruselas, 2.2.2012; entró en vigor el 27.9.2012); y el Tratado de Estabilidad, Coordinación y Gobernanza en la Unión Económica y Monetaria (Bruselas, 2.3.2012; entró en vigor el 1.1.2013).

$\mathrm{Y}$, finalmente, a esta lista debe ser añadida la Carta de los Derechos Fundamentales de la Unión Europea (Estrasburgo, 12.12.2007; entró en vigor el 1.12.2009), a la que nos hemos referido más arriba.

En la formulación de todos estos documentos jurídicos, España tuvo una activa participación, si bien el resultado de la misma ha sido desigual; en algunos casos logró introducir buena parte de sus propuestas, mientras que en otros sus posiciones apenas fueron atendidas. En este trabajo, sin embargo, no nos vamos a ocupar de todos estos textos, sino que — por razón de espacio — nos limitaremos a analizar la participación de España solamente en seis de ellos, los cuales, por otra parte, son los únicos que tienen propiamente la naturaleza jurídica de tratados de la UE: el Acta Única Europea, el Tratado de Maastricht, el Tratado de Ámsterdam, el Tratado de Niza, el Tratado por el que se establece una Constitución para Europa, y el Tratado de Lisboa. Se trata, pues, de tratados de diferente carácter y contenido material, todos los cuales, sin embargo, han tenido una relevancia especial en el devenir histórico de lo que es hoy la UE y, además, en todos ellos, de una manera u otra, España ha tenido una participación específica.

\section{A) El primer paso: el Acta Única Europea}

El primer tratado de reforma de las CCEE en cuya formulación pudo participar España es el Acta Única Europea. España había concluido y firmado su Tratado de Adhesión a las CCEE el 12 de junio de 1985, y pocos días después, se celebraría el Consejo Europeo de Milán, de 28 y 29 de junio, en el que se decidió convocar una Conferencia Intergubernamental para que abordase la difícil tarea de reformar los Tratados constitutivos. España, pues, no era aún miembro de pleno derecho de las CCEE, dado que el ingreso efectivo se produciría el primero de enero de 1986, y, sin embargo, fue invitada ya a participar de manera plena en el proceso de reforma que se iniciaba en el aquel momento. El Presidente del Gobierno era entonces el socialista Felipe González, que se encontraba en su segundo mandato. Así, Felipe González asistió al Consejo Europeo de Milán — primero al que asistía España- y el Gobierno estuvo también representado en las seis sesiones que llegó a celebrar la Conferencia 
Intergubernamental, a nivel ministerial, entre el 9 de septiembre y el 19 de noviembre de $1985 .{ }^{17}$

El Ministro de Asuntos Exteriores español, Francisco Fernández Ordóñez, se referiría después a la actitud de España, que fue claramente favorable a la reforma, tanto en lo referido a la profundización en la integración en el ámbito de las CCEE, como en lo referido al nuevo proceso de cooperación política en el ámbito de la política exterior y de seguridad. En el primer aspecto, la posición española trató de equilibrar el proceso de convergencia económica, añadiéndole un mayor contenido social y una función redistributiva de la riqueza, para asistir a las regiones y a los sectores sociales más desfavorecidos, con la introducción de la cohesión como un objetivo fundamental de las CCEE. Así, decía Fernández Ordóñez, en el debate sobre la autorización parlamentaria de la ratificación por España del Acta Única Europea, el 2 de octubre de 1986: «Desde el punto de vista español, creo que podemos apuntarnos un éxito en cuanto a la cohesión económica, entendida claramente como una reducción de las diferencias entre las distintas regiones. Este es un tema que interesa mucho a España.» ${ }^{18}$

En verdad, España tuvo una actitud muy positiva en el proceso de elaboración del Acta Única, hasta tal punto que, si bien su aprobación suponía ya algún cambio de los términos acordados en el Tratado de Adhesión que acaba de firmar con las CCEE, no opuso traba alguna a su firma y posterior ratificación. ${ }^{19}$ Para el Gobierno de España, el Tratado de Adhesión no estaba en peligro y, además, la nueva política de cohesión y el refuerzo financiero de los fondos estructurales entonces vigentes (el Fondo Europeo de Orientación y de Garantía Agrícola-Sección Orientación, el Fondo Social Europeo y el Fondo Europeo de Desarrollo Regional), eran una garantía y una compensación suficientes para el enorme esfuerzo realizado por España en la negociación previa sobre el Tratado de Adhesión. En los términos de Fernández Ordóñez: «Sencillamente, la filosofía que está defendiendo el Gobierno español es que entendemos que el mercado interior necesita unas estructuras de rectificación, que creemos en una

17 Sobre el proceso que llevó a la convocatoria de la Conferencia Intergubernamental de 1985 y su dinámica interna, véase: Aldecoa Luzarraga, F., «El Acta Única Europea. Primer paso incierto en la profundización comunitaria hacia la Unión Europea», Revista de Estudios Internacionales, vol. 7, n. ${ }^{\circ} 2$ (abril-junio 1986), pp. 543-563; Dinan, Desmond, «The Single European Act: Revitlising European Integration», en Laursen, Finn (ed.), Designing the European Union: From Paris to Lisbon (Houndmills: Palgrave Macmillan, 2012), pp. 124-146.

${ }^{18}$ Diario de Sesiones del Congreso de los Diputados, Año 1986, III Legislatura, Núm. 9, Sesión Plenaria núm. 8, celebrada el jueves, 2 de octubre de 1986; pp. 279-297.

19 Portugal, en cambio, hizo constar en al Acta final una declaración -Declaración del Gobierno de la República Portuguesa sobre el párrafo segundo del artículo 59 y el artículo 84 del Tratado CEEen la que se decía: «Portugal estima que el paso de la votación por unanimidad a la votación por mayoría cualificada en el párrafo segundo del artículo 59 y en el artículo 84, al no haber sido planteado en las negociaciones de adhesión de Portugal a la Comunidad y al modificar sustancialmente el acervo comunitario, no debe perjudicar los sectores sensibles y vitales de la economía portuguesa y que deberían adoptarse medidas transitorias especificas apropiadas cada vez que fuere necesario, a fin de impedir posibles efectos negativos para dichos sectores.» 
Europa basada en el mercado — pero no sólo en el mercado- y que estas estructuras de rectificación, que es el mecanismo de la cohesión, tienen que funcionar.» ${ }^{20}$

Sin embargo, las previsiones sobre la cohesión económica y social, que se incluyen como nuevo Título V del Tratado de la Comunidad Económica Europea, fueron tanto una compensación, una contrapartida obtenida por España en la negociación, como un complemento natural ya previsto por los proponentes de la reforma, para corregir las disfunciones que el mercado único podría generar en determinadas regiones. ${ }^{21}$

Tras esta primera participación en el proceso de reforma de las CCEE, España se sintió muy satisfecha. El proceso, además, fue también el primero que se produjo en la dirección de convertir la hasta entonces integración económica europea en una también- integración política. España autorizó la ratificación del Acta Única mediante la Ley Orgánica 4/1986, de 26 de noviembre, ${ }^{22}$ y presentó el instrumento de ratificación el 9 de diciembre de $1986 .{ }^{23}$ El Acta Única Europea entraría en vigor, finalmente, el primero de julio de 1987.

\section{B) La ciudadanía y la cohesión: el Tratado de Maastricht}

El Tratado de Maastricht vino a profundizar en la vía abierta por el Acta Única hacia la integración política, creando la Unión Europea. Así, el Tratado, firmado el 7 de febrero de 1992 en el palacio del gobierno provincial de la ciudad holandesa que le da su nombre, constituye una estructura política compleja — la Unión Europeabasada en tres pilares: un pilar de integración, en términos propios, formado por las tres Comunidades Europeas ya existentes — que constituyen, en realidad, el cuerpo central del nuevo edificio que se construye-, y dos pilares de cooperación política - uno sobre la política exterior y de seguridad, a lo que se añade el plan de crear, de manera progresiva, también una política de defensa, y otro sobre justicia y asuntos de interior- Sin embargo, el Tratado de Maastricht no sólo constituyó la Unión Europea con importantes competencias en materia de política exterior y de seguridad común, y de cooperación en justicia y asuntos de interior, sino que introdujo también relevantes modificaciones en el que en este momento pasa a ser denominado Tratado de la Comunidad Europea. Modificaciones en cuya propuesta y aprobación España tuvo un papel muy destacado.

La participación de España durante la fase de debate y formulación del Tratado de Maastricht — que coincidió, de nuevo, con la presidencia del Gobierno socialista de Felipe González, ahora en su tercer mandato— fue especialmente intensa en lo que

${ }^{20}$ Diario de Sesiones del Congreso de los Diputados, Año 1986, III Legislatura, Núm. 9, cit.

${ }^{21}$ Lamo de Espinosa, Emilio, «El Acta Única Europea y la Agricultura», Revista de Estudios Agro-Sociales, n. 146 (octubre-diciembre 1988), pp. 39-94.

22 Ley Orgánica 4/1986, de 26 de noviembre, por la que se autoriza la ratificación por España del Acta Única Europea, firmada en Luxemburgo el 17 de febrero de 1986. (BOE n. 288, 2.12.1986).

${ }^{23} B O E$ n. 158, 3.7.1987. 
se refiere a la aprobación de la política social, la política de cohesión, la ciudadanía europea - estas dos últimas fueron una iniciativa propia de España- y el Comité de las Regiones — resultado de las iniciativas de Alemania y España-. No fue, sin embargo, tan exitosa la apuesta de España por una política de defensa autónoma de la UE, en respaldo de la propuesta franco-alemana, ni en lo que se refiere a la delimitación de los criterios de convergencia exigidos para poder entrar en la tercera fase del establecimiento de la unión económica y monetaria — la introducción del euro-. Por otra parte, la política de cohesión no fue tampoco tan extensa como España pretendía y se vio limitada por las presiones contrarias del Reino Unido, Dinamarca y Holanda, quedándose reducida a la previsión de una financiación especial para proyectos en los sectores del medio ambiente, y de las redes transeuropeas en materia de infraestructuras del transporte. ${ }^{24}$

El Presidente del Gobierno, Felipe González, daría cuenta de todo ello en su comparecencia ante el Pleno del Congreso de los Diputados, el 17 de diciembre de 1991. En términos generales, para el Presidente González, los resultados obtenidos «son coherentes con lo que habíamos esperado y, por consiguiente, podemos transmitir claramente a la Cámara y a la opinión pública que son para los intereses de nuestro país muy satisfactorios». En términos más específicos, precisó el Presidente: «España ha participado activa y plenamente en este proceso y ha contribuido de manera decisiva a la configuración del mismo. Desde el estatuto de la ciudadanía europea, hasta el tema de la cohesión económica y social, pasando por la protección de los consumidores, o la política de seguridad y la política exterior, o el mismo desarrollo de la Unión Económica y Monetaria, nuestra participación ha sido intensa y activa». A lo que añadió: «la delegación española ha obtenido lo que ha planteado, prácticamente en su totalidad, en materia de cohesión económica y social. [... L La cohesión, en primer lugar, ha de ser tenida en cuenta en la formulación y en la aplicación de las políticas y de las acciones de la Comunidad. [...] En tercer lugar, se establece un fondo de cohesión antes del 31 de diciembre del año 1993 para cuestiones de medio ambiente y redes transeuropeas en el ámbito de la infraestructura de transportes para aquellos países que tengan una renta inferior al 90 por ciento de la media comunitaria [...] En cuarto lugar, la reconsideración en el año 1992 del volumen de los fondos estructurales. En quinto lugar, la flexibilización en la asignación de los medios financieros de estos fondos estructurales. En sexto lugar, la modulación de la cofinanciación de los programas y de los fondos de los proyectos estructurales. En séptimo lugar, el reconocimiento del principio de la capacidad contributiva de los Estados miembros en el sistema de recursos propios, con una corrección específica [...] para aquellos Estados miembros menos prósperos. [...] y en las nuevas competencias hemos logrado introducir algunos elementos que han sido específicamente

${ }^{24}$ Vid. una descripción detallada de los debates habidos en las dos Conferencias Intergubernamentales, en: CVCE, The Treaty on European Union, Intergovernmental negotiations (en: http://www.cvce.eu/en/ education/unit-content/-/unit/02bb76df-d066-4c08-a58a-d4686a3e68ff/454e5549-ca83-45d7-a97d$3 \mathrm{~d} 3683 \mathrm{c} 72 \mathrm{cbb}$ 
nuestros, en materia de educación o en materia de cultura y, finalmente, aunque había quedado descolgado en la última propuesta de la Presidencia, en materia de defensa de los consumidores». De la misma manera, concluyó González: «en el texto del Tratado las competencias nuevas en investigación y desarrollo tecnológico, en medio ambiente o en redes transeuropeas han respetado las exigencias españolas». ${ }^{25}$

Pero no todo fue un éxito tan llamativo y el propio Presidente hubo de reconocer lo magro de las conquistas en algunos terrenos en los que España había puesto grandes expectativas como, por ejemplo, la política social: «En política social hubiéramos deseado llegar a un acuerdo entre los doce, pero, ante la oposición frontal del Reino Unido, se ha buscado una fórmula complicada, y sin duda difícil de aplicar jurídicamente». ${ }^{26}$

La ratificación del Tratado de Maastricht planteaba algunas dudas sobre su posible compatibilidad con la Constitución de 1978, por lo que, tras el correspondiente informe del Consejo de Estado de 9 de abril de 1992, ${ }^{27}$ el Gobierno decidió requerir al Tribunal Constitucional para que se pronunciase acerca de la posible contradicción entre el Art. 13.2 de la Constitución Española y el Art. 8 B, apartado 1, del Tratado Constitutivo de la Comunidad Europea. El Tribunal Constitucional, en su Declaración de 1 de julio de 1992 — primera decisión relevante del alto Tribunal en materia de Derecho europeo- entendió, efectivamente, que el apartado 1 del Art. 8 B del Tratado de la Comunidad Europea, tal y como quedaba redactado por el Tratado de la Unión Europea, era contrario al Art. 13.2 de la Constitución Española, por cuanto atribuía derecho de sufragio pasivo en las elecciones municipales a los ciudadanos de la Unión Europea, no españoles, residentes en España, lo que obligaba a reformar la Constitución. Por otra parte, en este sentido, el Tribunal entendió también que el procedimiento de reforma constitucional que debería seguirse en este caso era el establecido en el art. 167 de la Constitución.

La Constitución española, pues, fue reformada el 27 de agosto de $1992,{ }^{28}$ y, así, la Ley Orgánica 10/1992, de 28 de diciembre, autorizó la ratificación del Tratado de Maastricht por España. ${ }^{29}$ Culminado el proceso de ratificación, el Tratado de Maastricht entró en vigor el primero de noviembre de 1993, prácticamente un año después de lo que se había previsto.

${ }_{25}$ Diario de Sesiones del Congreso de los Diputados, Año 1991, Núm. 155, Sesión Plenaria núm. 149, 17 de diciembre de 1991, pp. 7758 ss.

${ }^{26}$ Ibidem.

${ }_{27}$ Consejo de Estado, Dictamen sobre el Tratado de la Unión Europea firmado en Maastricht el 7 de febrero de 1992. Fecha de aprobación 9/4/1992. (En: http://www.boe.es/buscar/doc.php?id=CE-D-1992-421).

${ }^{28}$ Reforma del artículo 13, apartado 2, de la Constitución Española, de 27 de agosto de 1992. (BOE núm. 207, de 28 agosto 1992).

${ }^{29}$ Ley Orgánica 10/1992, de 28 de diciembre, por la que se autoriza la ratificación por España del Tratado de la Unión Europea. Firmado en Maastricht el 7 de febrero de 1992. (BOE núm. 312, de 29 diciembre 1992). 


\section{C) El papel exterior y la política social: el Tratado de Ámsterdam}

La formulación del Tratado de Ámsterdam vino exigida por dos factores determinantes: por un lado, la previsión del Artículo $\mathrm{N}$ del Tratado de Maastricht, el cual establecía que en 1996 se debía convocar una Conferencia Intergubernamental con el fin de valorar la eficacia de las reformas que se habían previsto en aquel Tratado y completarlas con las nuevas reformas que se considerase convenientes; y, por otro lado, la necesidad de realizar una reforma en la composición y funcionamiento de las instituciones, a fin de permitir la ampliación de la Unión a los Estados del centro y del Este de Europa, que habían ido abandonando los respectivos regímenes comunistas tras la caída del muro de Berlín, en noviembre de 1989, y la desmembración de la Unión Soviética.

En este sentido, el Consejo Europeo de Corfú, de 24-25 de junio de 1994, con el objetivo de preparar los debates, estableció un Grupo de Reflexión, que presidiría el diplomático español Carlos Westendorp, entonces Secretario de Estado para las Comunidades Europeas. El Grupo de Reflexión presentó su informe un año y medio más tarde, en el Consejo Europeo de Madrid, de 15-16 de diciembre de 1995 (coincidiendo con la segunda presidencia Española de la UE, bajo el cuarto Gobierno de Felipe González), y, desde entonces, las tres líneas programáticas generales diseñadas en este documento — acercar Europa a sus ciudadanos; permitir un mejor funcionamiento de la Unión y prepararla para su ampliación; dotar a la Unión de una capacidad de acción mayor en el exterior- sirvieron para orientar los trabajos de la Conferencia Intergubernamental. ${ }^{30}$ La Conferencia fue convocada por el Consejo Europeo de Turín, de 29 de marzo de 1996, el cual estableció su agenda de una manera detallada, pero con base en las propuestas del Grupo de Reflexión: una Unión más cercana a sus ciudadanos, unas instituciones más democráticas para una Unión más eficiente, y reforzar la capacidad para la acción exterior de la Unión. ${ }^{31}$ La Conferencia Intergubernamental culminó sus trabajos en el Consejo Europeo de Ámsterdam, de 16 y 17 de junio de 1997, poco más de un año después de su inauguración. Y el Tratado de Ámsterdam sería firmado el 2 de octubre de 1997, entrando en vigor el 1 de mayo de 1999, tras un proceso de ratificación carente de sobresaltos.

España tuvo una participación muy activa en el proceso de Ámsterdam desde su mismo inicio — dada la presencia de un español en la presidencia del Grupo de

30 Conferencia Intergubernamental de 1996. Informe del Grupo de Reflexión y otras referencias documentales. Secretaría General del Consejo de la Unión Europea, Brussels, 5 December 1995; Madrid European Council 15 and 16 December 1995. Presidency Conclusions. Part A. The Intergovernmental Conference. A Strategy for Europe. (En: http://www.consilium.europa.eu/en/european-council/conclusions/1993-2003).

31 European Council, Turin, 29 March 1996. Intergovernmental Conference. An Agenda for the Intergovernmental Conference. (En: http://www.consilium.europa.eu/en/european-council/conclusions/1993-2003). 
Reflexión-y hasta la aplicación posterior de las previsiones del Tratado, por cuanto otro español, Javier Solana, sería nombrado para ocupar el puesto de Secretario General del Consejo de la Unión Europea y Alto Representante para la Política Exterior y de Seguridad Común, el 18 de octubre de 1999; puesto en el que permanecería diez años, hasta el 30 de noviembre de 2009. Según el principal negociador español en el proceso de Amsterdam, el Embajador y Representante Permanente de España ante la UE, Javier Elorza, «[a]sí como España había sido observadora en el Acta Única, participante —y muy activa - en Maastricht, en Ámsterdam fuimos los que lideramos gran parte de la operación. En aquel momento había un ajuste de cuentas pendiente; desde Ioannina, España y el Reino Unido habían querido reponderar los votos en el Consejo, o variar el umbral de la mayoría de bloqueo para defenderse frente a la entrada de tres nuevos socios [Austria, Finlandia y Suecia entraron en la UE en enero de 1995], que tenían poblaciones muy pequeñas y recibían un número de votos muy, muy significativo en relación con su población». ${ }^{32}$

La prioridad para España en aquel momento, pues, era el reequilibrio institucional y su posición en el juego de poder en la Unión. España había asumido el resultado de las difíciles negociaciones sobre las perspectivas financieras celebradas recientemente, hasta el año 1999, y, por lo tanto, no le interesaba reabrir en aquel momento la cuestión de la financiación de los Fondos europeos, dado que el resultado podría haber sido desfavorable. Y, desde luego, a España le interesaba igualmente el refuerzo de la capacidad competencial de la Unión y, muy especialmente, de la Comunidad Europea. ${ }^{33}$

En esta línea, el que fue entonces presidente del Grupo de Reflexión, Carlos Westendorp, sostuvo también que las prioridades para España en el proceso de formulación del Tratado de Ámsterdam eran el empleo, la lucha contra el terrorismo, y comunitarizar todas las cuestiones que tienen que ver con el cruce de las fronteras exteriores de la Unión, como el régimen de la extranjería, la política de inmigración y asilo, las normas comunes sobre el control de fronteras. ${ }^{34} \mathrm{Y}$ el balance final sobre lo conseguido, lo hizo el entonces Ministro de Asuntos Exteriores, Abel Matutes, ante el Congreso de los Diputados, en el debate sobre la

32 Elorza Cavengt, Francisco Javier, «El Tratado de Amsterdam: Valoración para España», en Díez de Velasco Vallejo, Manuel (ed.), La Unión Europea tras la reforma (Santander: Universidad de Cantabria - Parlamento de Cantabria, 2000), pp. 219-238. Y, en similares términos, en: Elorza Cavengt, Francisco Javier, «El Tratado de Amsterdam: Una evaluación española», en: Matutes, Abel et al., España y la negociación del Tratado de Amsterdam (Madrid: Estudios de Política Exterior, 1998), pp. 35-58.

33 Véase un relato muy detallado de la posición de España en los debates de la Conferencia Intergubernamental de 1996-1997 en: Elorza CAVEngt, Francisco Javier, «El Tratado de Amsterdam», cit.

34 Carlos Westendorp, «La posición española ante la reforma de los tratados de la Unión europea». Conferencia pronunciada en la Real Academia de Jurisprudencia y Legislación el 26 de marzo de 1996, en Revista de Actividades, Textos y Documentos de la Política Exterior Española (Madrid: Ministerio de Asuntos Exteriores, Oficina de Información Diplomática, 15.07.2005). (En: http://www.mae.es/portal/ revista_oid/revista_oid_96/www.mae.es/mae/textos/OID/ATDPE/ATDPE1996/discursos/Mae/CW/ cw020.htm. 
autorización de la firma del Tratado de Ámsterdam. ${ }^{35}$ En la visión del Gobierno de España, cuatro eran los ámbitos principales en los que se había centrado el esfuerzo negociador: en primer lugar, el acercamiento de la Unión a los ciudadanos; en segundo lugar, la creación de un espacio de libertad, seguridad y justicia; en tercer lugar, el fortalecimiento de la política exterior de la Unión, para hacerla más eficaz y coherente; y, en cuarto lugar, la dotación de mayor legitimidad a sus instituciones.

En lo que se refiere al acercamiento de la Unión a los ciudadanos, el Ministro destacó dos objetivos de la delegación española que fueron satisfechos: la promoción del empleo, mediante el reforzamiento de la coordinación de las políticas nacionales de empleo y la adopción de medidas de incentivo para impulsar la acción de los Estados miembros; y el tratamiento especial que las regiones ultraperiféricas pasan a recibir entonces, gracias al nuevo Art. 227 (tras la remuneración: Art. 299), que incluye a las Islas Canarias, «y tengo que decir —añadió el Ministro- que la propuesta española para dichas regiones ultraperiféricas ha sido plenamente recogida en ese nuevo texto». En lo que se refiere al empleo, España logró la introducción en el TCE de un nuevo Título («Título VI bis: Empleo»), consiguiendo, además, que la financiación dedicada a este objetivo no se detrajese de los fondos dedicados a la cohesión. ${ }^{36}$ Pero, quizá lo más significativo fuese aquí la lucha de España por la afirmación del principio de igualdad, que quedó finalmente incluido en diversos preceptos de la política social — la igualdad entre hombres y mujeres en lo que respecta a las oportunidades en el mercado laboral y al trato en el trabajo- y como principio inspirador de carácter general (Art. 119 TCE en aquel momento; hoy Art. 157 TFUE). Como dijo entonces el Embajador Elorza, el Gobierno de Felipe González había incorporado la ciudadanía en el Tratado de Maastricht y ahora el Gobierno de José María Aznar quería dejar la igualdad «como algo que quedara irremediablemente anclado en el Tratado de una manera real y no simplemente por el juego de la jurisprudencia». ${ }^{37}$

En lo que se refiere a la creación de un espacio de libertad, seguridad y justicia, Matutes destacó la integración del acuerdo de Schengen en las previsiones del Tratado de la Comunidad Europea y, por lo tanto, en el marco del primer pilar de la Unión Europea. Pero, de acuerdo con el Ministro, «[l] os intereses de España en el marco del contencioso sobre Gibraltar han quedado plenamente protegidos, ya que podremos mantener los controles al tráfico de personas procedentes del Reino Unido y de los territorios que representa en la Unión en cualquier punto de entrada del territorio español». Por otra parte, había otro tema de extraordinaria relevancia y en el que España tuvo que enfrentarse duramente a otros Estados, y que el Ministro no mencionó en el debate parlamentario: la concesión de asilo político a ciudadanos prove-

35 Diario de Sesiones del Congreso de los Diputados, Año 1998, VI Legislatura, Núm. 171, Sesión Plenaria núm. 166, 18 de junio de 1998; pp. 9201-9216.

36 Elorza Cavengt, Francisco Javier, «El Tratado de Amsterdam», cit.

37 Ibidem. 
nientes de otro Estado miembro de la UE. Para España, dada la protección de los derechos y libertades fundamentales existente en todos los Estados miembros de la $\mathrm{UE}$, era inconcebible que tal asilo político pudiera concederse, $\mathrm{y}$, sin embargo, esa era la situación que se producía entonces con dos terroristas de ETA que habían solicitado asilo político en Bélgica. España logró finalmente que se añadiese un Protocolo al Tratado por el que se impedía la admisión a trámite de solicitudes de asilo en este tipo de casos y se afirmaba que «los Estados miembros constituyen recíprocamente países de origen seguros a todos los efectos jurídicos y prácticos en relación con asuntos de asilo». ${ }^{38}$

En lo que se refiere al fortalecimiento de la política exterior de la Unión, Matutes destacó la creación de la unidad de planificación y el establecimiento de la figura del Alto Representante de la política exterior y de seguridad común, que va a ser, al mismo tiempo, Secretario General del Consejo, y el relevante papel que se le atribuía en la preparación, formulación y puesta en práctica de las decisiones del Consejo en este terreno. Lo que no pudo decir entonces el Ministro Matutes, porque ello tendría lugar un año más tarde, es que ese puesto iba a ser ocupado por un español, Javier Solana, nombrado el 18 de octubre de 1999, que era en aquel momento Secretario General de la OTAN.

$Y$, en fin, en lo que se refiere a la dotación de mayor legitimidad a las instituciones de la UE, explicó el Ministro que esta mayor legitimidad venía determinada por el reforzamiento de los poderes del Parlamento Europeo, con la ampliación del ámbito material del procedimiento de codecisión y también con la extensión del ámbito material de la decisión por mayoría cualificada. Pero, en lo que se refiere específicamente a España, afirmó el Ministro: «Los intereses españoles en las instituciones de una Europa a Quince quedan preservados, pues se reconoce que España es un caso especial que debe quedar solucionado antes de la ampliación en lo que al problema institucional del voto ponderado, del peso de España en el Consejo hace referencia». Además, «[l] propuesta española para el reforzamiento del Comité de las Regiones fue retenida casi en su totalidad, dándole una mayor autonomía y reforzando sus competencias». Y, en fin, «[e]l nuevo Tratado de Ámsterdam —cuestión importante- consagra en su articulado el principio de la cohesión económica y social, manteniendo todo el acervo existente tanto sobre los fondos estructurales como sobre el Fondo de Cohesión».

En opinión del Ministro, pues, la conclusión no podía ser otra que «[l]o logrado tras la negociación en la Conferencia Intergubernamental ha sido muy satisfac-

38 Protocolo sobre asilo a nacionales de los Estados miembros de la Unión Europea. Los Estado que se opusieron a la propuesta española fueron principalmente Bélgica, Países Bajos, Irlanda y Grecia. Bélgica, de hecho, añadió dos Declaraciones al Acta final, por las que pretendía condicionar las previsiones del Protocolo: Declaración (n. ${ }^{\circ}$ 48) relativa al Protocolo sobre asilo a nacionales de los Estados miembros de la Unión Europea, y Declaración (n. $\left.{ }^{\circ} 49\right)$ sobre la letra d) del artículo único del Protocolo sobre asilo a nacionales de los Estados miembros de la Unión Europea. Véase, al respecto, ElorzA Cavengt, Francisco Javier, «El Tratado de Amsterdam», cit. 
torio [...] El éxito alcanzado por el Gobierno español en estas largas e intensas negociaciones ha sido el éxito de todas Sus Señorías, ha sido el éxito de todos los españoles». ${ }^{39}$

El Tratado de Ámsterdam, sin embargo, a pesar de los logros conseguidos en varios ámbitos —algunos de ellos subrayados por el Ministro Matutes en su comparecencia ante el Congreso de los Diputados-, no logró alcanzar el objetivo principal que tenía programado: la reforma de las instituciones para permitir la ampliación de la UE hacia el centro y el Este de Europa. Y ello, de manera principal, como consecuencia de la ruptura del eje franco-alemán y del consenso sustantivo existente desde el inicio de las CCEE sobre el peso político y la representación institucional de los tres Estados grandes fundadores - Francia, Alemania e Italia-. Este fracaso obligaba a la convocatoria de una nueva Conferencia Intergubernamental y a la redacción de un nuevo tratado de reforma.

El propio Tratado de Ámsterdam estableció una previsión formal a este respecto: el «Protocolo sobre las instituciones en la perspectiva de la ampliación de la Unión Europea», en el cual se preveía, en primer lugar, que en la fecha de entrada en vigor de la primera ampliación de la Unión, la Comisión comprendería un nacional de cada uno de los Estados miembros, siempre que para esa fecha se hubiese modificado la ponderación de votos en el Consejo de una manera aceptable para todos los Estados miembros, bien mediante una nueva ponderación de los votos, o bien mediante una doble mayoría, teniendo en cuenta, en especial, la compensación a aquellos Estados miembros que renunciasen — como era el caso de España- a la posibilidad de designar un segundo miembro de la Comisión. Y, en segundo lugar, preveía también que, al menos un año antes de que el número de Estados miembros de la Unión Europea excediese de veinte, se convocaría una Conferencia Intergubernamental, a fin de efectuar una revisión global de las disposiciones de los Tratados sobre la composición y el funcionamiento de las instituciones.

El Gobierno de España logró imponer una declaración complementaria a este respecto ( «Declaración n. ${ }^{\circ}$ 50, relativa al Protocolo sobre las instituciones en la perspectiva de la ampliación de la Unión Europea»), por la que se acordó que, hasta la entrada en vigor de la primera ampliación, se prorrogaría la Decisión del Consejo de 29 de marzo de 1994 y que, antes de esa fecha, se encontraría una solución al caso especial de España. ${ }^{40}$ En realidad, lo que se pretendía es que se compensase a España por la renuncia a su segundo comisario con un mayor número de votos en el Consejo, y que, mientras tanto, España conservase el derecho de veto sobre sobre asuntos rele-

39 Ibidem.

40 La Decisión del Consejo de 29 de marzo de 1994, más conocida como el «Compromiso de Ioannina», estableció que un Estado podía impedir que el Consejo se pronunciase por mayoría cualificada, haciendo que esta institución tuviese que reconsiderar la cuestión, tratando de encontrar una solución satisfactoria en un plazo de tiempo razonable. (En: http://eur-lex.europa.eu/summary/glossary/ioannina_compromise.html?locale=es). 
vantes para ella, en los que antes se votaba por unanimidad y ahora se pasaba a requerir sólo la mayoría cualificada. ${ }^{41}$

Finalmente, la ratificación del Tratado de Ámsterdam no resultó dificultosa en ningún Estado miembro, a diferencia de lo que había ocurrido con el Tratado de Maastricht. Sólo dos Estados sometieron a referéndum previo su ratificación, sin embargo, el resultado fue positivo en ambos casos. Irlanda fue el primero en votar, el 22 de mayo de 1999, y el «sí» triunfó con el 61,74\% de los votos. Dinamarca votaría el 28 de mayo de 1999 y, de nuevo, el «sí» triunfaría, en este caso con el 55,1\% de los votos. En los demás casos se siguió el procedimiento parlamentario de ratificación. España otorgaría su autorización para la ratificación del Tratado de Ámsterdam el 16 de diciembre de $1998,{ }^{42}$ y, finalmente, el Tratado de Ámsterdam entraría en vigor el primero de mayo de 1999, casi dos años después de su firma.

\section{D) El refuerzo de la posición institucional: el Tratado de Niza}

Con el fin de cerrar los denominados «flecos de Ámsterdam», el Consejo Europeo de Colonia, de 3 y 4 de junio de 1999, decidió convocar una Conferencia Intergubernamental, que debería finalizar sus trabajos a finales del año 2000. De acuerdo con el Consejo Europeo, la Conferencia debería centrar sus trabajos sobre tres temas capitales: a) la magnitud y composición de la Comisión Europea; $b$ ) la ponderación de votos en el Consejo (nueva ponderación, o introducción de la doble mayoría; umbral para decisiones por mayoría cualificada); y c) la cuestión de la posible extensión del sistema de votación por mayoría cualificada en el Consejo.

La Conferencia Intergubernamental que elaboró el Tratado de Niza, pues, fue inaugurada el 14 de febrero de 2000 y se cerró en el Consejo Europeo de Niza, de 7 , 8 y 9 de diciembre de 2000 ( ¡a las 4 de la mañana del día 10!). Fue una Conferencia difícil, con graves divergencias entre los Estados, con la desaparición del tradicional eje director Francia-Alemania; con Francia — que ocupó la presidencia rotatoria de la UE en la segunda fase de la Conferencia - más preocupada por la defensa de sus propios intereses que de intermediar para conseguir acuerdos; con Alemania exigiendo una nueva posición institucional más acorde con su nuevo y mayor peso poblacional, tras su reunificación; con los Estados grandes - a los que, en general, quiso asociarse España - muy preocupados por la pérdida de su peso tradicional en las CCEE que iba a suponer el ingreso de 12 nuevos Estados del centro y del Este de Europa, todos ellos Estados pequeños, excepto Polonia; con los Estados pequeños

41 Vid., en este sentido, Javier Elorza, «La batalla de Niza», en El País, 21 diciembre 2000. (En: http://elpais.com/diario/2000/12/21/opinion/977353203_850215.html).

42 Ley Orgánica 9/1998, de 16 de diciembre, por la que se autoriza la ratificación por España del Tratado de Ámsterdam por el que se modifican el Tratado de la Unión Europea, los Tratados constitutivos de las Comunidades Europeas y determinados actos conexos, firmado en Ámsterdam el día 2 de octubre de 1997. (BOE núm. 301, de 17 de diciembre de 1998, pp. 42266-42330). 
tradicionales obsesionados con la idea de no perder su posición institucional con las reformas que se avecinaban; $y$, en fin, con España ejerciendo un papel de negociador duro, asociándose con frecuencia a las posiciones del Reino Unido, lo que sorprendió a todos, dado el tradicional enfoque integracionista que siempre había mantenido España y que ahora parecía acercarse más a las posiciones euroescépticas, contrarias a la profundización en el proceso de integración política y defensoras de los intereses nacionales por encima de los de la Unión. ${ }^{43}$ España continuaba así la línea negociadora dura que el Gobierno de Aznar había iniciado en el debate sobre el Tratado de Ámsterdam. ${ }^{44}$

Así, la posición de España en los debates de la Conferencia Internacional que llevaron a la formulación del Tratado de Niza tendió fundamentalmente a reforzar su papel como Estado mediano-grande, en lo que hace referencia a su peso en el proceso decisorio de la Unión, y a mantener lo conseguido hasta entonces, en términos de financiación. Como reconocería entonces Javier Elorza, Embajador y Representante Permanente de España ante la UE y, de nuevo, director efectivo de la delegación española en aquella negociación — como ya lo había sido en Ámsterdam—, «España tenía tres objetivos centrales en Niza. En primer lugar, lograr un reequilibrado de la cuota de poder en el Consejo a través de la reponderación de los votos en favor de los cinco países más poblados. Esta negociación era vital para permitir a España disponer de los votos suficientes para poder negociar en los temas de mayoría cualificada [...] En segundo lugar, España luchó y consiguió en Niza mantener la unanimidad para la aprobación de las próximas perspectivas financieras a partir del 1 de enero del 2007 [...] En tercer lugar, España ha conseguido preservar algunas unanimidades [...] imprescindibles al afectar a la acción del Gobierno y a los grandes equilibrios macroeconómicos, sociales y políticos de nuestro país». ${ }^{45}$

43 Para Javier ElorZA, «Desde un punto de vista español, el texto del Tratado de Niza es muy favorable, como ha señalado un informe interno de la Comisión, que estima a España y al Reino Unido como los dos ganadores de Niza» (ElorZa, Javier, «La batalla de Niza», El País, 21 de diciembre de 2000 (En: http://elpais.com/diario/2000/12/21/opinion/977353203_850215.html). En similar sentido: Yataganas, Xénophon A., «The Treaty of Nice. The Sharing of Power and the Institutional Balance in the European Union: A Continental Perspective», Cambridge, 8 March 2001. (En: http://www.jeanmonnetprogram.org/archive/papers/01/010101.html).

44 Elorza Cavengt, Francisco Javier, «El Tratado de Amsterdam», cit. Véase también: Bradley, Kieran, «Institutional Design in the Treaty of Nice», Common Market Law Review, 38 (2001), pp. 1095-1124; GutiÉrREZ EsPADA, Cesáreo, «Una reforma “difícil pero productiva”: La revisión institucional en el Tratado de Niza», Revista de Derecho Comunitario Europeo, 9 (2001), pp. 27-75; MANGAS, Araceli, «El Tratado de Niza: Los complejos equilibrios en la futura Unión ampliada», Cursos de Derecho Internacional y Relaciones Internacionales de Vitoria-Gasteiz, 1 (2001), pp. 245-248; MARTÍNEZ Sierra, José M., «El Tratado de Niza», Revista Española de Derecho Constitucional, 62 (2001), pp. 221 260; Plechanovová, Bela, «The Treaty of Nice and the Distribution of Votes in the Council - Voting Power Consequences for the EU after the Oncoming Enlargement», European Integration online Papers (EIoP), 7 (2003), en: http://eiop.or.at/eiop/texte/2003-006a.htm.

45 ElorZA, Javier, «La batalla de Niza», cit. 
José María Aznar, del Partido Popular, que se encontraba en su segundo mandato, era entonces el Presidente del Gobierno y gozaba de la fuerza que le daba el respaldo interno de la mayoría absoluta en las Cortes Generales. Para el Gobierno de Aznar, obtener una mejora en la reponderación de los votos en el Consejo, le permitiría a España disponer de una posición ventajosa para poder negociar mejor en todas aquellas materias que, en el Tratado de Ámsterdam y, ahora, en el Tratado de Niza, se pasaban de la unanimidad a la mayoría cualificada. Como explicó entonces el Embajador Elorza: «España pasará a partir del 1 de enero del 2005 de tener ocho votos en el Consejo sobre un total de 87 (es decir, un 9,2\%) a 27 votos sobre un total de 237 (esto es, el 11,4\%). Esta mayor reponderación permitirá a España obtener la consideración de país grande, por primera vez en la historia de la Comunidad. España podrá constituir minoría de bloqueo con similar fuerza y efectos que cualquiera de los cuatro grandes restantes». ${ }^{46}$

En términos absolutos, sin embargo, el éxito de España no había sido tan grande, en la medida en que lo que logró España en el Tratado de Niza fue equilibrar una situación que había perdido en el Tratado de Ámsterdam, como efecto de la ampliación de la UE a 15 Estados, tras la entrada de Austria, Finlandia y Suecia en enero de 1995. Así, cuando España entró en las CCEE obtuvo 8 votos ponderados en el Consejo, sobre un total 76, lo que suponía el 10,53\% del total de los votos ponderados. En el Tratado de Ámsterdam, en 1997, sin embargo, ese peso institucional se redujo al mantener España sus 8 votos ponderados, pero ahora sobre un total de 87 votos ponderados en el Consejo, lo que suponía retroceder al 9,20\% del total. En Niza, pues, se recuperó el terreno perdido en Ámsterdam e, incluso, se aumentó también el total de votos con respecto a lo que se había conseguido inicialmente en el Tratado de Adhesión y en el Tratado de Maastricht. Sin embargo, es en términos relativos donde fue mayor el avance de España; es decir, en su posición con respecto a los cuatro Estados grandes de la Unión. Así, si en el Tratado de Adhesión, en el Tratado de Maastricht y en el Tratado de Ámsterdam la diferencia porcentual en votos con respecto, por ejemplo, a Francia, era de 2,63, de 2,63 y de 2,30 puntos porcentuales, respectivamente, en el Tratado de Niza esa diferencia pasó a ser sólo de 0,85 puntos porcentuales, lo que efectivamente ponía a España casi en pie de igualdad con los cuatro Estados grandes.

En lo que se refiere al número de miembros en el Parlamento Europeo, las cosas no fueron exactamente igual para España. Así, en términos absolutos, España obtuvo en el Tratado de Adhesión 60 diputados, lo que representaba el 11,58\% del total de los 518 diputados de entonces. Esta cifra se aumentó a 64 diputados en el Tratado de Maastricht, si bien en el porcentaje se redujo un poco, pasando a ser el 11,30\% del total de los 567 diputados del momento. En el Tratado de Ámsterdam se mantuvo la cifra de 64 diputados, si bien el aumento del número total de diputados a 626 supuso que el peso de los diputados españoles se redujese un poco más, pasado a ser

46 Ibidem. 
el 10,22\% del total. Y, en Niza, al reducirse el número de diputados atribuidos a España, que pasan ahora a ser sólo 50 diputados, su peso pasa a ser sólo el 9,35\% del total. Y, en términos relativos, en lo que se refiere al Parlamento Europeo, podría decirse que España salió aún peor tratada, dado que, si en el Tratado de Adhesión el número de diputados españoles era 3,78 puntos porcentuales menor que el de Francia — como referente-, en el Tratado de Maastricht la diferencia creció hasta 4,04 puntos, y si bien en el Tratado de Ámsterdam esta diferencia se redujo a 3,68 puntos, en Niza volvió a crecer hasta 4,11 puntos porcentuales, la mayor diferencia existente desde la entrada de España en las CCEE hasta el presente, en lo que se refiere al peso relativo del número de diputados españoles en el Parlamento Europeo. La reducción en el número de diputados en el Parlamento Europeo fue, pues, el precio que hubo de pagar España para aumentar su peso en el seno del Consejo. Claro que, desde el punto de vista del papel de ambas instituciones en el equilibrio institucional de la Unión, no puede decirse en absoluto que la estrategia seguida entonces por España hubiese sido equivocada.

En verdad, el hecho de que España exigiese el mantenimiento del voto por unanimidad en el Consejo en muchas materias iba, con toda evidencia, en contra de la línea general de extender progresivamente el voto por mayoría cualificada y de dotar así de mayor eficiencia al proceso decisorio comunitario. Para para España, empero, el mantenimiento de la unanimidad en muchos de los ámbitos en cuestión, siquiera fuese durante un cierto período transitorio, era una garantía que le permitía asegurar una mejor financiación y un mayor peso institucional. Así, España no sólo consiguió en Niza mantener la unanimidad para la aprobación de las perspectivas financieras que se aprobarían a partir del 1 de enero del 2007, y del correspondiente acuerdo interinstitucional, sino que logró también que, hasta que aquellas perspectivas financieras estuvieran aprobadas, los Fondos Estructurales y el Fondo de Cohesión no pasasen a la decisión por mayoría cualificada. El acuerdo forzado por España exigió además que cuando el Consejo decidiese por mayoría cualificada, a partir del 1 de enero de 2007, se requiriese el previo dictamen conforme del Parlamento Europeo y la consulta previa al Comité Económico y Social y al Comité de las Regiones. ${ }^{47}$

En los términos del Embajador Elorza, una vez más, «[e]sta fórmula, propuesta por la delegación española y aceptada a regañadientes por los [Estados] contribuyentes netos, permitirá a España obtener nuevamente un importante flujo de transferencias económicas en concepto de cohesión económica y social que coadyuvará a la convergencia real, elemento clave para colmar los déficits estructurales de España». ${ }^{48}$

En fin, con el apoyo de Portugal y Grecia, España añadió una Declaración al Acta final de la Conferencia Intergubernamental, por la cual se establecía que las perspectivas financieras plurianuales aplicables a partir del 1 de enero de 2007 , tendrían la

${ }^{47}$ Ministerio de Asuntos Exteriores, Secretaría de Estado de Asuntos Europeos, Tratado de Niza:

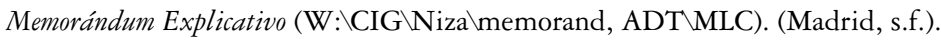

48 ElorZA, Javier, «La batalla de Niza», cit. 
misma duración que las perspectivas financieras vigentes en aquel momento. ${ }^{49}$ Lo cual dio lugar a que Dinamarca, Alemania, los Países Bajos y Austria añadiesen al Acta una «contradeclaración» — y ello es verdaderamente inusual_- por la cual se afirmaba que la Declaración de España, Portugal y Grecia no tenía (no podía tener) por efecto prejuzgar la acción de la Comisión Europea, especialmente su derecho de iniciativa. $^{50}$

España logró también mantener la votación por unanimidad en otros ámbitos que el Gobierno Aznar consideraba estratégicos y que afectaban a los grandes equilibrios macroeconómicos, sociales y políticos del país. Así la fiscalidad, la protección y la seguridad social, la ordenación del territorio, la gestión del agua, o las fuentes de suministro energéticas. En este sentido, el comentario del Embajador Elorza era contundente: «La convergencia se debe hacer naturalmente y no ser fruto de "armonizaciones artificiales" que respondan únicamente a la conocida técnica de la "exportación de costes".» ${ }^{51}$

España mantuvo también una posición que fue igualmente decisoria en otros ámbitos materiales del Tratado de Niza. Un informe muy detallado del Ministerio de Asuntos Exteriores sobre la actuación de España en el seno de la Conferencia Intergubernamental del año 2000, realizado entonces, dio cuenta de todo ello. ${ }^{52}$ Así, en el terreno de las cooperaciones reforzadas, España apoyó la flexibilización del procedimiento — muy rígido_- que se había aprobado por el tratado de Ámsterdam, si bien logró introducir una garantía adicional muy importante, como es el requisito del dictamen conforme del Parlamento Europeo, cuando la cooperación reforzada se refiriese a un ámbito regido por el procedimiento de codecisión. ${ }^{53}$

No resultaría similarmente exitosa España, en cambio, en lo que se refiere a otras de sus propuestas, o a las propuestas de otros Estados a las que se adhirió. Así, España no tuvo éxito en su propuesta de dotar al Comité de las Regiones del estatuto de institución, reconociéndole, como consecuencia, legitimación activa para interponer recursos ante el Tribunal de Justicia de la Unión para salvaguardar sus prerrogativas; ${ }^{54}$ cosa que sí se conseguiría en el Tratado de Lisboa. Y tampoco tendría mucho éxito en lo que se refiere a sus posiciones con respecto a la reforma de la Comisión Europea.

49 Declaración (n. ${ }^{\circ}$ 2) de Grecia, España y Portugal relativa al artículo 161 del Tratado constitutivo de la Comunidad Europea.

50 Declaración (n. ${ }^{\circ}$ 3) de Dinamarca, Alemania, los Países Bajos y Austria relativa al artículo 161 del Tratado constitutivo de la Comunidad Europea.

51 Elorza, Javier, «La batalla de Niza», cit. La defensa a ultranza de la unanimidad en estos terrenos era algo que España había ya defendido con éxito en el debate sobre el Tratado de Ámsterdam (Elorza Cavengt, Francisco Javier, «El Tratado de Ámsterdam», cit.).

52 Ministerio de Asuntos Exteriores, Tratado de Niza, cit.

53 Ministerio de Asuntos Exteriores, Tratado de Niza, cit., p. 28. Este aspecto sería también destacado por el Ministro Josep Piqué en su defensa de la ratificación del Tratado de Niza en el pleno del Congreso de los Diputados (Diario de Sesiones del Congreso de los Diputados, Año 2001, VII Legislatura, Núm. 102, Sesión plenaria núm. 97, 13 de septiembre de 2001; pp. 4953-4968).

54 Ministerio de Asuntos Exteriores, Tratado de Niza, cit., p. 24. 
Así, España pretendió que, si se limitaba el número de miembros de la Comisión, los Estados grandes deberían tener siempre un miembro cada uno, mientras que debería establecerse un turno rotatorio para los Estados pequeños. Esta propuesta sería finalmente rechazada, decidiéndose entonces establecer que el turno rotatorio afectase a todos los Estados por igual, tanto a los grandes como a los pequeños. Tampoco salió adelante la propuesta de que la estructura interna de la Comisión se dividiese de manera jerárquica, entre un grupo superior de Comisarios — «senior commissioners»y un grupo inferior — «junior commissioners»—. ${ }^{55}$ Por lo demás, en términos generales, se puede decir España apoyó la gran mayoría de las reformas del Tratado de Niza que finalmente salieron adelante.

Pero el Tratado de Niza — como en anteriores ocasiones - no cerró de manera plena la cuestión de la reforma de la UE y volvió a dejar la puerta abierta a una nueva reforma futura. Así, la «Declaración relativa al futuro de la Unión» (n. ${ }^{\circ} 23$ ), que acompaña al Tratado, si bien entendía que «con la ratificación del Tratado de Niza, la Unión Europea habrá completado los cambios institucionales necesarios para la adhesión de nuevos Estados miembros», pensaba también que, una vez abierto el camino a la ampliación, era necesario realizar un debate más amplio y profundo sobre el futuro de la Unión Europea. En este sentido, la Declaración de Niza convocaba a «un amplio debate con todas las partes interesadas: los representantes de los Parlamentos nacionales y del conjunto de la opinión pública, tales como los círculos políticos, económicos y universitarios, los representantes de la sociedad civil, etc.». Debate que debería realizarse a lo largo del 2001 y al que se debería invitar igualmente a los que entonces eran Estados candidatos a la adhesión.

Finalmente, la ratificación del Tratado de Niza no fue tan problemática como había resultado la ratificación del Tratado de Maastricht, sin embargo, de nuevo Irlanda encalló en el primer intento. Así, Irlanda celebró un primer referéndum el 7 de junio 2001 y el «no» triunfó por el 53,87\% de los votos. Tras un replanteamiento interno de la cuestión, Irlanda decidió presentar en el Consejo Europeo de Sevilla, de 21 y 22 de junio de 2002, una declaración («Declaración Nacional de Irlanda») en la que se venía a decir que lo que creaba problema a los irlandeses era la decisión de caminar progresivamente en la definición de una política europea de defensa, por cuanto ello podría afectar a la tradicional neutralidad de Irlanda. ${ }^{56}$ El Consejo Europeo aprobó entonces una Declaración en la que, en sustancia, se clarificaba que «el Tratado de la Unión Europea dispone que toda decisión de construir una defensa común se adoptará de conformidad con las respectivas normas constitucionales de los Estados

55 Bar, Antonio, «The Number of Members of the Commission: A Possible Reform?», en E. Best, M. Gray, A. Stubb (eds.), Rethinking the European Union: IGC 2000 and Beyond (Maastricht: EIPA, 2000), pp. 77-103; Yataganas, Xénophon A., «The Treaty of Nice», cit.

${ }^{56}$ Consejo Europeo de Sevilla, 21 y 22 de junio de 2002, Conclusiones de la Presidencia (13463/02, POLGEN 52), Anexo III: Declaración Nacional de Irlanda. 
miembros». ${ }^{57}$ Esto dicho, Irlanda volvió a someter a referéndum la decisión de ratificar el Tratado de Niza, el 19 de octubre de 2002, y en esta ocasión el «sí» triunfó por el $62,89 \%$ de los votos.

En el caso de España, tras el dictamen positivo del Consejo de Estado, ${ }^{58}$ el Tratado de Niza fue sometido a la ratificación de las Cortes en octubre de 2001, y la autorización final para la ratificación sería aprobada por la Ley Orgánica 3/2001, de 6 de noviembre. ${ }^{59}$ El Tratado de Niza, finalmente, entró en vigor el primero de febrero de 2003, dos años después de haber sido firmado.

La posición notablemente favorable conseguida por España en Niza, sin embargo, no duró mucho tiempo, dado que el 16 de abril de 2003 se firmaría en Atenas el Tratado de adhesión de los diez nuevos Estados miembros del centro y del Este de Europa, el cual, a partir de su entrada en vigor, el primero de mayo de 2004, volvería a reducir la cuota de poder obtenida por España. Así, tras la entrada en vigor del Tratado de Adhesión de 2003, España conservaría sus 27 votos ponderados en el Consejo, pero, al aumentarse el número total de votos hasta 321, con la entrada de los nuevos Estados, el peso del voto español pasó a ser sólo el 8,41\% del total (frente al $11,39 \%$ conseguido en Niza), lo que volvió a aumentar el diferencial con respecto al voto de los cuatro Estados grandes a 3,83 puntos (frente a los 0,85 puntos de Niza). Y, en lo que se refiere al Parlamento Europeo, a España se le dieron entonces 4 diputados más, pasando a tener un total de 54 diputados. Ello, sin embargo, no aumento su porcentaje, dado que el número total de diputados del Parlamento Europeo pasó en aquel momento a ser de 732, por lo que los diputados españoles pasaron a ser sólo el 7,40\% del total (frente al 9,35\% de Niza). El diferencial con respecto al porcentaje de diputados de los Estados grandes - manteniendo a Francia como referente- - sin embargo, mejoró un poco, pasando a ser de 3,26 puntos (frente a los 4,11 de Niza). ${ }^{60}$

El Tratado de Adhesión de 2003, pues, vino a rebajar el elevado posicionamiento institucional que España había conseguido en el Tratado de Niza, volviendo a darle el papel de Estado mediano. Posición ésta que se le atribuyó entonces también a Polonia, Estado al que se le dio el mismo número de votos en el Consejo y el mismo número de diputados en el Parlamento Europeo que a España, a pesar de que este Estado es, en realidad, más pequeño que España y tenía en aquel momento (año 2003) 38,2 millones de habitantes, frente a los 42,72 millones de España.

57 Consejo Europeo de Sevilla, 21 y 22 de junio de 2002, cit. Anexo IV: Declaración del Consejo Europeo.

58 Consejo de Estado, Dictamen sobre el Tratado Niza (880/2001), de 19 de abril de 2001.

59 Ley Orgánica 3/2001, de 6 de noviembre, por la que se autoriza la ratificación por España del Tratado de Niza por el que se modifican el Tratado de la Unión Europea, los Tratados Constitutivos de las Comunidades Europeas y determinados actos conexos, firmado en Niza el día 26 de febrero de 2001. (BOE núm. 267, 7 noviembre 2001).

${ }^{60}$ Acta relativa a las condiciones de adhesión de los diez nuevos Estados miembros, aneja al Tratado de adhesión firmado en Atenas, el 16.4.2003 (DO L 236, de 23.9.2003). 


\section{E) De la firmeza a la cesión: la Constitución europea}

El Tratado de Niza — como hemos visto en páginas anteriores— dejó abierta la puerta a una reforma sustantiva de la Unión que debería asegurar su futuro como una Unión políticamente integrada. Así, la "Declaración relativa al futuro de la Unión» (n. ${ }^{\circ} 23$ ), que acompañaba al Tratado, establecía que era necesario realizar un debate más amplio y profundo sobre el futuro de la Unión Europea, en el que deberían participar tanto las instituciones nacionales, como la sociedad civil en su conjunto. ${ }^{61} \mathrm{El}$ debate, que se extendió a todo lo largo del año 2001, concluyó en el Consejo Europeo de Laeken, del 14 y 15 de diciembre de 2001, el cual aprobó una extensa declaración ( "Declaración de Laeken sobre el futuro de la Unión Europea») en la que, en sustancia, se venía a afirmar que la Unión debe «aproximar las Instituciones europeas al ciudadano»; unas instituciones europeas que, además, debían ser «menos lentas y rígidas y, sobre todo, más eficientes y transparentes». ${ }^{62}$ La Declaración de Laeken formulaba, además, una larga serie de preguntas — más de 65- sobre las necesarias reformas a realizar en el seno de la Unión y proponía que éstas fuesen contestadas, en términos políticos, por una convención que debería ser convocada al efecto y formada por representantes de los gobiernos de los Estados miembros, de los Parlamentos nacionales, del Parlamento Europeo y de la Comisión. Respuestas que luego deberían ser revisadas y formuladas en términos jurídicos por una Conferencia Intergubernamental, único órgano capaz de formular una reforma de los Tratados, tal y como preveía el Art. 48 del Tratado de la Unión Europea.

La Convención prevista en la Declaración de Laeken se reunió en Bruselas, en la sede del Parlamento Europeo, del 28 de febrero de 2002 al 10 de julio de 2003, y a ella se invitó también a participar a los Estados del centro y del Este de Europa, entonces candidatos a la adhesión. La Convención, sin embargo, no se limitó a contestar a las preguntas que se le hacían, sino que, excediéndose del mandato recibido, formuló ya un texto articulado, un borrador completo de tratado constitucional. Concluidos sus trabajos, la Convención presentó su proyecto al Consejo Europeo en su reunión de Salónica, de 19 y 20 de junio de 2003, lo que permitió la convocatoria de la Conferencia Intergubernamental. ${ }^{63}$ Esta última fue inaugurada en Roma, el 4 de octubre de 2003, bajo la presidencia de Italia, y se clausuró en Bruselas, el 18 de junio de 2004, bajo la presidencia de Irlanda. El resultado de la Conferencia Intergubernamental fue la formulación del «Tratado por el que se establece una Constitución para Europa», que sería firmado solemnemente, por todos los Jefes de Estado o de Gobierno de los Estados miembros, en Roma, el 29 de octubre de 2004 . $^{64}$

${ }^{61}$ DO C 80, 10.3.2001, p. 85.

${ }^{62}$ Consejo Europeo de Laeken, 14 y 15 de diciembre de 2001, Conclusiones de la Presidencia. Anexo I: Declaración de Laeken sobre el futuro de la Unión Europea (SN 300/1/01 Rev 1), pp. 19-26.

${ }^{63}$ Consejo Europeo de Salónica, 19 y 20 de junio de 2003, Conclusiones de la Presidencia, pp. 1-2.

64 Tratado por el que se establece una Constitución para Europa (DO C 310, 16.12.2004). 
Tanto en la Convención como en la Conferencia Intergubernamental que le siguió, España tuvo una participación muy activa. En lo que se refiere a la Convención, el inicio de sus trabajos, en febrero de 2002, coincidió con el desempeño de la tercera presidencia española de la UE —enero-junio de 2002-, que ejercía entonces el Gobierno del Partido Popular, presidido por José María Aznar, que se encontraba en su segundo mandato. Así, Aznar presidió la sesión inaugural de la Convención, en su condición de Presidente Consejo Europeo, al lado de Pat Cox, Presidente del Parlamento Europeo, y de Romano Prodi, Presidente de la Comisión. En la Convención participaron destacados representantes españoles, como miembros de la delegación del Parlamento Europeo (Íñigo Méndez de Vigo, del PPE, y Carlos Carnero, del PSE), de las Cortes Generales (los diputados Josep Borrell y Diego López Garrido, del PSOE; y Gabriel Cisneros y el senador Alejandro Muñoz Alonso, del PP), y, desde luego, del Gobierno español (Ana Palacio, Ministra de Asuntos Exteriores, Alfonso Dastis, Secretario General de Asuntos Europeos, y Carlos Bastarreche, Representante Permanente de España ante la UE). Además, fueron propuestos como observadores del Comité de las Regiones, Eduardo Zaplana, Presidente de la Comunidad Valenciana, Manuel Chaves, Presidente de Andalucía, y Ramón Valcárcel, Presidente de Murcia. Íñigo Méndez de Vigo y Alfonso Dastis, además, serían miembros del Presidium de la Convención, y Méndez de Vigo presidiría también el grupo de trabajo n. ${ }^{\circ} 1$, sobre la subsidiariedad, y el círculo de discusión sobre los recursos propios de la Unión. ${ }^{65}$

Pero, fue el papel del Gobierno de España y de sus representantes lo que dejó verdaderamente una impronta en este proceso de reforma de la estructura constitucional de la UE. ${ }^{66}$ La posición de España en la Convención vino a ser una continuación de la sostenida durante el debate del Tratado de Niza. España pretendía entonces mantener el equilibrio institucional que se había adquirido en Niza y que le colocaba en una posición muy cercana a la de los Estados grandes. Ello, primero, le llevó a

${ }^{65}$ Los representantes españoles en la Convención - Méndez de Vigo, Carnero, Palacio, Dastis, Borrell, Cisneros, López Garrido_- actuando en representación de sus respectivas entidades, llegarían a proponer 16 documentos sustantivos para el debate, sobre asuntos tales como el presupuesto en la Constitución Europea (CONV 38/02); el reparto de competencias (CONV 56/02); la solidaridad y derechos humanos (CONV 329/02); la Carta de los Derechos fundamentales de la UE (CONV 368/02); la política social y el empleo (CONV 394/02); la igualdad de género (CONV 454/02); la religión (CONV 501/03); los poderes regionales y locales (CONV 517/03); la tipología de actos y la jerarquía de las normas en la UE (CONV 517/03); la libertad religiosa y la laicidad (CONV 587/03); las instituciones de la Unión (CONV 591/03); la cooperación policial operativa (CONV 600/03); los métodos de trabajo del Tribunal de Justicia y del Tribunal de Primera Instancia (CONV 620/03); el debate sobre el futuro de Europa (CONV 690/03); las regiones estructuralmente desfavorecidas (CONV 694/03); el reparto de escaños en el Parlamento Europeo y la ponderación de votos en el Consejo (CONV 757/03); y la ordenación del Tratado Constitucional (CONV 787/03). Sobre el desarrollo interno de la Convención, véase: Borrell, Josep; Carnero, Carlos; López Garrido, Diego, Construyendo la Constitución Europea: Crónica Política de la Convención (Madrid: Real Instituto Elcano, 2003).

${ }_{66}$ Véase la propuesta conjunta a la Convención de Ana Palacio (Gobierno de España) y Peter Hain (Gobierno del Reino Unido), «Las instituciones de la Unión» (CONV 591/03). 
mantener una reserva sobre la aprobación del proyecto de Constitución europea elaborado por la Convención y concluido en julio de 2003, y, después, a sostener una dura posición negociadora en la Conferencia Intergubernamental, hasta el punto de ser España uno de los Estados causantes del fracaso de la primera fase de la misma, bajo la presidencia de italiana, que se cerró en octubre de 2003.

En los aspectos formales, y como cuestión de principio, España consideraba que la Convención constitucional no estaba legitimada para realizar un trabajo de reforma de los Tratados —ello sólo corresponde a la Conferencia Intergubernamental-y, además, se había extralimitado con respecto al mandato que había recibido del Consejo Europeo de Laeken. Y, desde un punto de vista material, si bien España se manifestaba de acuerdo con muchas de las previsiones incluidas en el proyecto de la Convención, consideraba, sin embargo, que el sistema de votación en el Consejo allí adoptado venía a romper con el acuerdo tan costosamente conseguido en de Niza y con el equilibrio institucional allí establecido.

El Gobierno español consideraba, en este sentido, que todo quedaba abierto a la discusión en la Conferencia Intergubernamental, al mismo tiempo que expresaba «su razonable inquietud respecto al capítulo institucional», por lo que sostenía que «lo más razonable es mantener en vigor el consenso institucional del actual Tratado [de Niza]». Así, lo expuso el Presidente Aznar ante el Congreso de los Diputados: «el mantenimiento del equilibrio institucional actual preserva una justa representación de España en la Unión, y ya sólo por esto quedaría justificada la posición que va a defender el Gobierno hasta el final de la presidencia. Pero el Gobierno español entiende que el acuerdo de Niza además de bueno para España lo es para otros países y facilita su representación, de manera que puede decirse que es lo que más conviene a la Unión en su conjunto.» ${ }^{67}$

España mantuvo esta dura posición de partida a todo lo largo de la primera fase de la Conferencia Intergubernamental, impidiendo que se lograse el acuerdo antes del fin del año 2003, como había sido planeado. Sin embargo, el Gobierno español manifestaba también su frustración por el hecho de que ni su posición fuese comprendida, ni sus propuestas de reforma finales fuesen aceptadas. Así, aunque España entendía que «desanudar el capítulo institucional de Niza supondría levantar serios obstáculos al proyecto de nueva constitución, porque nunca es fácil rehacer un nuevo consenso no sólo a veinticinco sino a veintisiete países», y que «[al] defender el equi-

${ }^{67}$ Comparecencia del Presidente del Gobierno, José María Aznar, ante el Pleno del Congreso de los Diputados, para informar sobre el Consejo Europeo de Bruselas, de 16 y 17 de octubre de 2003, y el comienzo de la Conferencia Intergubernamental 2003-2004. (Diario de Sesiones del Congreso de los Diputados, Año 2003, VII Legislatura, Núm. 288, Sesión plenaria núm. 275, 23 de octubre de 2003, pp. 15175 ss.). En la misma línea se había manifestado, unos días antes, Ana Palacio, Ministra de Asuntos Exteriores, ante la Comisión Mixta para la Unión Europea, para informar también sobre al Consejo Europeo de Bruselas, de 16 y 17 de octubre de2003, y el comienzo de la Conferencia Intergubernamental. (Diario de Sesiones de las Cortes Generales, Comisión Mixta para la Unión Europea, Año 2003, VII Legislatura, Núm. 151, Sesión núm. 58, 7 de octubre de 2003). 
librio institucional de Niza hemos defendido el interés europeo», y que, en fin, «[c] uesta aceptar que el principio histórico del voto ponderado sea repentinamente la fuente de todos los males que atenazan el desarrollo político y económico de nuestro continente», a pesar de todo ello, se avino finalmente a prescindir del voto ponderado e hizo también su propuesta de doble mayoría, si bien con unos porcentajes diferentes a los aprobados por la Convención y a los propuestos por la Presidencia italiana y otros Estados.

Así, frente al proyecto de la Convención, que proponía que la mayoría cualificada se alcanzase cuando votasen a favor de la propuesta la mayoría de Estados (51\%) que representase al menos los 3/5 de la población (60\%) de la UE, cuando la iniciativa partiese de la Comisión o del Ministro de Asuntos Exteriores de la UE; España propuso que la mayoría cualificada se alcanzase cuando votasen a favor de la propuesta la mayoría de Estados (51\%) que representase al menos 2/3 de la población (66\%) de la UE. El objetivo de España, pues, era conseguir que la mayoría cualificada requiriese el respaldo del mayor porcentaje de población posible, de tal manera que hubiese que contar con ella para cualquier votación mayoritaria. Sin embargo, la estrategia no era demasiado acertada, dado que ello obligaba también a tener que contar siempre con los Estados grandes para cualquier votación. Con menor porcentaje de población y mayor número de Estados detrás de cada votación, en cambio, España hubiese podido asociar a su posición a los Estados pequeños sin necesidad de tener que contar con el apoyo de los grandes. Pero, para España, el objetivo era en aquel momento ser más el pequeño de los grandes — un Estado mediano-grande, como lo había conseguido con la reponderación de votos en el Tratado de Niza-, que ser el grande de los pequeños. ${ }^{68}$

El cambio del contexto político, sin embargo, terminaría por facilitar el acuerdo. Así, la Presidencia rotatoria italiana fue sustituida por la irlandesa en enero de 2004, y ésta adoptó una diferente y eficaz estrategia, de perfil bajo y negociaciones previas antes de llegar a las reuniones de los ministros y los jefes de gobierno; y el Gobierno de España cambió también, tras el terrible atentado terrorista del 11 de marzo de 2004 y las elecciones generales del día 14, tres días después.

El nuevo Gobierno español, presidido por José Luis Rodríguez Zapatero, adoptó una posición más flexible en la negociación que la que había adoptado el Gobierno de José María Aznar, y terminó por aceptar la propuesta hecha por la Presidencia irlande-

${ }^{68}$ La propuesta de la Presidencia italiana, y también la de Alemania, era que la mayoría cualificada se alcanzase cuando votasen a favor de la propuesta la mayoría de los Estados (51\%) que representase al menos el $62 \%$ de la población de la UE. Sobre esta cuestión de la ponderación de votos, véanse los detallados análisis de Powell, Charles, «El gobierno español ante el proyecto de Tratado Constitucional», Análisis del Real Instituto Elcano (ARI), 90 (2003); Torreblanca, José Ignacio, «Votar y vetar en la Unión: una interpretación de la posición española en la CIG 2003», Análisis del Real Instituto Elcano (ARI), 121 (2003); Delgado-Iribarren, Manuel «La Convención, Niza y el voto en el Consejo de la Unión Europea», Análisis del Real Instituto Elcano (ARI) 129 (2003); Powell, Charles, «El Consejo Europeo de Bruselas [12 y 13 de diciembre de 2003], o la negociación que nunca existió», Análisis del Real Instituto Elcano (ARI) 152 (2003). 
sa, que es la que finalmente pasó al articulado del Tratado constitucional y luego al Tratado de Lisboa. La propuesta consistió en que la mayoría cualificada se alcanzase cuando votasen a favor de la propuesta un mínimo del 55\% de los Estados, que incluyese al menos a quince de ellos, y que representase como mínimo el $65 \%$ de la población de la UE, cuando la propuesta partiese de la Comisión o del Ministro de Asuntos Exteriores de la Unión. De todas formas, como reconoció el Presidente Zapatero, la negociación fue «una negociación ardua, ha sido una negociación dura a veces y también tensa». Y si esto fue así en términos generales, lo fue especialmente en la negociación sobre el capítulo institucional, «una de las cuestiones más difíciles y más prolongadas de las que se han discutido en el Consejo Europeo». Pero, para el Presidente, «hemos llegado a una fórmula plenamente satisfactoria»; fórmula en la que «España ve mejorada sustancialmente su posición respecto a la propuesta de la Convención». ${ }^{69}$

Sin embargo, no es del todo cierto que ello fuese así, sobre todo si se valora lo obtenido en comparación con los resultados de Niza. Pero, por si quedase alguna duda al respecto, el Presidente lo argumentó con detalle: «Durante toda nuestra historia en la Unión, España ha mantenido la aspiración de verse reconocida la capacidad de influencia de los países grandes. Lo hemos logrado, porque hoy, a partir de la Constitución, España, con Francia e Italia, más Portugal o Grecia, tiene la facultad de intervención o de bloquear cualquier decisión en salvaguarda de las políticas que como país mediterráneo más nos interesen. Y también puede España, con Francia y Alemania, más cualquier otro país, bloquear cualquier decisión en salvaguarda de las políticas que como país perteneciente al corazón de Europa nos interesen». ${ }^{70}$

El Presidente Zapatero, en su explicación ante el Congreso de los Diputados, se encargó de detallar también las otras aportaciones concretas que España había realizado al proyecto constitucional, sobre todo, claro es, en la segunda fase de la Conferencia Intergubernamental, cuando él ya había llegado al Gobierno. En este sentido, destacó Zapatero (a) el compromiso de que, durante la etapa transitoria, hasta que la totalidad de las previsiones de la Constitución entrasen en vigor y se adoptase la decisión europea por la que se fijase la composición definitiva del Parlamento Europeo - la legislatura 2004-2009_- España podría contar con cuatro diputados más, pasando a tener $54 .^{71}$ (b) La adopción de una Declaración en la que se establece que el combate contra la violencia de género pasa a ser un objetivo común de todas las

${ }^{69}$ Comparecencia del Presidente del Gobierno, José Luis Rodríguez Zapatero, ante el pleno del Congreso de los Diputados, para informar sobre el Consejo Europeo de Bruselas, de 17 y 18 de junio de 2004, y del cierre de la Conferencia Intergubernamental de 2003-2004. (Diario de Sesiones del Congreso de los Diputados, Año 2004, VIII Legislatura, Núm. 20, Sesión plenaria núm. 19, 23 de junio de 2004, pp. 796-803).

${ }^{70}$ Ibidem.

71 Protocolo (n. 34) sobre las disposiciones transitorias relativas a las instituciones y órganos de la Unión, y Declaración (n. 40) relativa al Protocolo sobre las disposiciones transitorias relativas a las instituciones y órganos de la Unión. 
políticas de la Unión. ${ }^{72}$ (c) El reconocimiento de la posibilidad de hacer traducciones del Tratado a otras lenguas que determinasen los Estados miembros y que tuviesen el estatuto de lengua oficial en la totalidad o en parte de su territorio, y que esas traducciones tuviesen el reconocimiento de traducción oficial (Art. IV-448).$^{73}$ (d) La mejora del régimen económico de las Islas Canarias como región ultraperiférica de la UE (Art. III-424). Y (e) la previsión de que el Tratado constitucional se aplicase a Gibraltar, sin que ello supusiese modificación alguna de las posiciones tradicionales de España y del Reino Unido al respecto. ${ }^{74}$

De acuerdo con el Presidente Zapatero, «hemos logrado una gran Constitución para todos los europeos, porque considero que es un excelente Tratado para Europa y, por serlo así, es un excelente Tratado para España». Y concluía: «La Unión, largo tiempo asociada al mercado interior o a la unión económica y monetaria, proclama ahora su clara ambición como comunidad política democrática, basada en valores comunes y en el concepto de ciudadanía europea.» ${ }^{75}$

La actuación posterior del Gobierno Zapatero, sin embargo, no fue muy coherente con su visión positiva del Tratado constitucional, como tampoco lo fue la de otros dirigentes europeos. Así, el Tratado fue firmado solemnemente por todos los Jefes de Estado o de Gobierno de los Estados miembros en Roma, el 29 de octubre de 2004, $y$, sin embargo, al poco tiempo de la firma, los líderes políticos que habían conseguido el difícil acuerdo daban la sensación de haber quedado agotados por el esfuerzo, o de haber dado el sí de mala gana. Así, en algunos casos, decidieron referir la responsabilidad final de la ratificación del Tratado a un referéndum, buscando con ello más trasladar el peso de esta responsabilidad a otras espaldas, que conseguir la necesaria legitimación popular. Es así como en España (el 20 de febrero de 2005), en Francia (el 29 de mayo de 2005), en los Países Bajos (el 1 de junio de 2005), y en Luxemburgo (el 10 de julio 2005), se celebraron referéndums de ratificación sin que los respectivos Gobiernos hiciesen, hasta el último minuto, el esfuerzo necesario para conseguir el apoyo que requería la aprobación popular del Tratado constitucional. Y el resultado no pudo ser peor. El Tratado fue rechazado en Francia y en los Países Bajos, y en España se registró la más baja participación popular conseguida hasta ese momento.

72 En realidad, la Declaración se refiere a la «violencia doméstica en todas sus formas», y no sólo impone la lucha contra la misma como un objetivo de las políticas de la UE, sino que obliga también a que «los Estados miembros adopten todas las medidas necesarias para prevenir y castigar estos actos delictivos y para prestar apoyo y protección a las víctimas». (Declaración [n. 13] relativa al artículo III116). La Declaración desarrollaba la previsión del Art. III-116 del Tratado constitucional, en la que se establecía que, en todas las acciones de la UE, ésta «tratará de eliminar las desigualdades entre la mujer y el hombre y de promover su igualdad».

${ }^{73}$ La Declaración (n. 29) relativa al apartado 2 del artículo IV-448, entendía, además, que las previsiones del artículo IV-448 contribuían a cumplir el objetivo de respetar la riqueza de la diversidad cultural y lingüística de la Unión.

${ }^{74}$ Declaración (n. 45) del Reino de España y del Reino Unido de Gran Bretaña e Irlanda del Norte.

75 Diario de Sesiones del Congreso de los Diputados, Año 2003, VII Legislatura, Núm. 288, Sesión plenaria núm. 275, 23 de octubre de 2003, cit. 
A pesar de todo, el proceso de ratificación siguió hasta bien entrado el año 2006 y, en total, 18 Estados llegaron a ratificar el Tratado constitucional (16 por vía parlamentaria y 2 por referéndum: España y Luxemburgo). ${ }^{76}$

En el caso de España, el Gobierno Zapatero decidió, en primer lugar, someter a consulta del Tribunal Constitucional, en noviembre de 2004, la posible existencia de contradicción entre la Constitución española y los artículos del Tratado por el que se establece una Constitución para Europa número I-6, que establecía la primacía del Derecho de la Unión sobre el Derecho de los Estados miembros; número II-111, referido al ámbito de aplicación de la Carta de los Derechos Fundamentales de la UE; y número II-112, referido al alcance e interpretación de los derechos y principios contenidos en la Carta; así como la posible suficiencia del Art. 93 de la Constitución Española como vía para la prestación del consentimiento del Estado para la ratificación de este Tratado y, en su caso, la posible vía a seguir para reformar la Constitución española a estos efectos. En su Declaración del 13 de diciembre de 2004 - la segunda del alto Tribunal español sobre la compatibilidad de un Tratado constitutivo de la UE con la Constitución española-, el Tribunal Constitucional entendió que no existía contradicción alguna entre la Constitución española y los preceptos del Tratado constitucional mencionados y que, además, el art. 93 de la Constitución española era suficiente para la prestación del consentimiento del Estado para la ratificación del Tratado. Esto dicho, el Tribunal Constitucional entendió también que no procedía hacer declaración alguna sobre la cuestión de qué cauce habría de ser seguido en el caso de que hubiese sido necesaria la reforma de la Constitución española. ${ }^{77}$

El Presidente Zapatero, una vez conocido el dictamen del Tribunal Constitucional, decidió convocar un referéndum consultivo sobre la decisión de ratificar el Tratado constitucional, ${ }^{78}$ llevando a la práctica la promesa de convocar un referéndum a estos efectos que ya había hecho también el Gobierno Aznar en octubre de $2003 .{ }^{79} \mathrm{El}$ referéndum se celebró el 20 de febrero de 2005 y el resultado fue desalentador. Es verdad que el sí triunfó por amplia mayoría (el 76,73\% de los votos), sin embargo, la abstención fue elevadísima (el 57,68\%), la más alta registrada hasta ese momento

${ }^{76}$ El último Estado en ratificar el Tratado constitucional, en vía parlamentaria, fue Finlandia, el 12 de mayo de 2006, justo un año después del «no» francés.

77 Declaración del Pleno del Tribunal Constitucional 1/2004, de 13 de diciembre de 2004. Requerimiento 6603-2004, formulado por el Gobierno de la Nación, acerca de la constitucionalidad de los artículos I-6, II-111 y II-112 del Tratado por el que se establece una Constitución para Europa, firmado en Roma el 29 de octubre de 2004. (BOE núm. 3, Suplemento, 4 enero 2005, pp. 5 ss.).

${ }^{78}$ Real Decreto 5/2005, de 14 de enero, por el que se somete a referéndum consultivo de la Nación la decisión política de ratificar el Tratado por el que se establece una Constitución para Europa (BOE núm. 13, de 15 de enero de 2005, pp. 1627 ss.).

79 Así lo propuso la Ministra de Asuntos Exteriores, Ana Palacio, en su comparecencia ante la Comisión Mixta para la Unión Europea, para informar sobre al Consejo Europeo de Bruselas, de 16 y 17 de octubre de 2003, y el comienzo de la Conferencia Intergubernamental 2003-2004. (Diario de Sesiones de las Cortes Generales, Comisión Mixta para la Unión Europea, Año 2003, VII Legislatura, Núm. 151, Sesión núm. 58, 7 de octubre de 2003). 
en España en un proceso electoral similar. Y el motivo estaba muy claro, lo especificaron los propios ciudadanos españoles en una encuesta realizada por la UE sólo un día después del referéndum: el $30 \%$ de los abstencionistas dijo que no había ido a votar porque no tuvo información suficiente sobre el Tratado constitucional. Pero, lo que es quizá más significativo, de aquellos que fueron a votar y votaron sí, sólo el $25 \%$ dijo haberlo hecho porque estaba de acuerdo con la Constitución europea, mientras que el $41 \%$ dijo haberlo hecho porque tenía una opinión positiva, en términos generales, sobre la Unión Europea. Es decir, los ciudadanos españoles dijeron que no habían tenido información suficiente sobre la Constitución europea que se les sometía a referéndum y ello, como es claro, sólo podía ser responsabilidad del Gobierno Zapatero. ${ }^{80}$ Finalmente, la autorización para la ratificación por España del Tratado constitucional fue emitida por la Ley Orgánica 1/2005, de 20 de mayo. ${ }^{81}$

\section{F) Debilidad y reubicación: el Tratado de Lisboa}

La elaboración del Tratado de Lisboa se realizó en el seno de una Conferencia Intergubernamental que se inauguró en Bruselas, el 23 de julio de 2007, y se concluyó en el Consejo Europeo informal de Lisboa de los días 18 y 19 de octubre de 2007. En la reunión inaugural, la Presidencia portuguesa presentó ya un primer proyecto articulado de lo que por entonces se denominaba «Tratado de Reforma», elaborado en apenas cuatro semanas sobre el mandato del Consejo Europeo de junio. A partir de entonces, la Conferencia se reuniría en dos niveles: por un lado, se reunieron los Ministros de Asuntos Exteriores (sólo en tres ocasiones) ${ }^{82}$ y, por otro, se reunieron los miembros del Grupo de Expertos Jurídicos, que fueron quienes hicieron el grueso del

${ }^{80}$ Comisión Europea, Eurobarómetro, «La Constitución Europea: Encuesta post-referéndum en España», Flash Eurobarómetro, 168 (Marzo 2005). Fecha realización de las entrevistas: 21-22 Febrero 2005. Y similar resultado se obtuvo en el caso de los Países Bajos, si bien en este caso, la falta de información (declarada por el 32\% de los votantes), llevó a los votantes a votar no al texto constitucional (61,54\% de los votantes). (European Commission, Eurobarometer, «The European Constitution: post-referendum survey in The Netherlands», Flash Eurobarometer, 172 (June 2005). Fieldwork: 02/04 June 2005). En el caso de Francia, en cambio, los ciudadanos franceses dijeron votar no al Tratado constitucional, por estar preocupados por la situación económica del país y el elevado desempleo (31\% de los votantes), es decir, no porque estuviesen verdaderamente en contra del mismo, sino porque estaban en contra de la política económica del Presidente Chirac, al que querían así castigar con su voto negativo. (European Commission, Eurobarometer, «The European Constitution: Post-referendum survey in France», Flash Eurobarometer, 171 (June 2005). Fieldwork: 30-31 May 2005).

${ }^{81}$ Ley Orgánica $1 / 2005$, de 20 de mayo, por la que se autoriza la ratificación por España del Tratado por el que se establece una Constitución para Europa, firmado en Roma el 29 de octubre de 2004. (BOE núm. 121, 21 mayo 2005).

${ }^{82}$ La primera reunión fue la inaugural, de Bruselas, el 23 de julio de 2007. La segunda reunión fue la reunión informal de Ministros de Asuntos Exteriores (Gymnich), de Viana do Castelo (7-8 septiembre 2007), y la tercera reunión fue en Luxemburgo (15-16 octubre 2007), con motivo de la celebración del Consejo de Asuntos Generales y Relaciones Exteriores, para preparar la Cumbre Informal de Lisboa. 
trabajo. ${ }^{83}$ Así, los pocos aspectos problemáticos que quedaban pendientes de resolución, tras el acuerdo general conseguido bajo la Presidencia alemana, fueron resueltos con cierta agilidad bajo la Presidencia portuguesa, en las reuniones de los expertos jurídicos y en la última reunión de los ministros, que tuvo lugar en Luxemburgo, el 15 y 16 de octubre de 2007; todos, en realidad, excepto dos. De esta manera, cuando el Consejo Europeo informal se reunió en Lisboa para poner fin a la Conferencia Intergubernamental, el 18 y 19 de octubre de 2007, además de algunas cuestiones menores, sólo dos temas requirieron un último y costoso esfuerzo para llegar al acuerdo final: a) el sistema de votación en el Consejo, al que Polonia venía oponiéndose de manera persistente, desde la llegada de los hermanos Kaczyński a la presidencia de la República y a la presidencia del Gobierno; y b) la composición del Parlamento Europeo, debido a la oposición de última hora de Italia a la propuesta de distribución de escaños entre los Estados, realizada por el propio Parlamento pocos días antes de la reunión de Lisboa. ${ }^{84} \mathrm{El}$ acuerdo final se conseguiría a la una de la madrugada del día 19 de octubre, por un lado, concediendo a Polonia lo que fue un a modo de «acuerdo de Ioannina II», que figura en la Declaración n. ${ }^{\circ} 7$ del Acta Final de la Conferencia; y, por otro lado, aumentando en uno — que es atribuido a Italia — el número máximo de 750 escaños en el Parlamento Europeo que había previsto la Resolución parlamentaria del 11 de octubre de 2007.

En el caso del Tratado de Lisboa, no puede decirse que España hubiese hecho aportación particular alguna digna de ser reseñada. Por el contrario, como había ocurrido en la última fase de la Conferencia Intergubernamental que llevó a la aprobación del Tratado constitucional, el Gobierno Zapatero se limitó a sumarse al consenso general sobre la práctica totalidad de sus previsiones, las cuales, por otra parte, no eran si no las que ya se habían aprobado en Roma, en octubre de 2004, y que formaban parte del contenido material del Tratado constitucional. Esto fue lo que llevó al entonces Ministro de Asuntos Exteriores español, Miguel Ángel Moratinos, a afirmar que el apoyo del Gobierno al Tratado de Lisboa se debía a que éste era «reflejo en gran medida del non nato Tratado constitucional que fue refrendado por los ciudadanos españoles el 20 de febrero de 2005». En este sentido, según el Ministro, «[e]l Tratado de Lisboa contiene notables —y subrayo-, notables avances en materia institucional que permitirán un mejor funcionamiento de la Unión, como el paso de la unanimidad a la mayoría cualificada en casi 50 casos, o la generalización del procedimiento de codecisión entre el Consejo y el Parlamento Europeo para la adopción de las leyes europeas. El tratado refuerza también la dimensión democrática de la Unión con la introducción de medidas como la iniciativa legislativa popular, el control del respeto de la subsidiariedad por los parlamentos nacionales, o la mayor

${ }^{83}$ Los expertos juristas celebraron 18 reuniones, entre el 24 de julio y el 13 de septiembre, e hicieron público su proyecto de Tratado el 5 de octubre de 2007.

84 Resolución del Parlamento Europeo, de 11 de octubre de 2007, sobre la composición del Parlamento Europeo (2007/2169(INI)). 
participación de las regiones en las actividades de la Unión, y, sobre todo, con la incorporación al derecho de la Unión de la Carta de Derechos Fundamentales.» ${ }^{85}$

Sin embargo, la ratificación del Tratado de Lisboa fue un proceso muy largo y atormentado, por motivos estrictamente políticos. Así, aunque sólo un Estado decidió someterlo a referéndum - Irlanda_- el proceso de ratificación duró dos años, desde su firma en Lisboa, el 13 de diciembre de 2007, hasta su entrada en vigor, el primero de diciembre de 2009. En este largo camino, el Tratado hubo de superar un referéndum negativo en Irlanda y la necesidad de su repetición, un recurso de inconstitucionalidad ante el Tribunal Constitucional Federal alemán, dos recursos de inconstitucionalidad ante el Tribunal Constitucional de la República Checa, y el capricho político de dos presidentes - Lech Kaczyński, de Polonia, y Václav Klaus, de la República Checa- que, sin más excusa que su mera voluntad política, se negaron a ratificar el Tratado, poniendo todo tipo de obstáculos hasta que no les quedó más remedio que hacerlo. ${ }^{86}$ En cambio, en el caso de España, la ratificación del Tratado de Lisboa no planteó problema alguno, dado que las dudas jurídicas habían sido ya resueltas por el Tribunal Constitucional en su Declaración del 13 de diciembre de 2004 sobre el Tratado constitucional, cuyas previsiones se limita a recoger el Tratado de Lisboa. ${ }^{87}$ Así, la autorización para su ratificación fue emitida por la Ley Orgánica $1 / 2008$, de 30 de julio. ${ }^{88}$

Y, si bien España no hizo aportación sustantiva alguna a la formulación del Tratado de Lisboa, sí tuvo, en cambio, un papel relevante en su aplicación y desarrollo, dado que fue el primer Estado miembro en ejercer la Presidencia de la Unión tras su entrada en vigor, el primero de diciembre de 2009. Así, España no sólo ejerció la Presidencia rotatoria de la Unión en el primer semestre del año 2010, correspondiendo ese papel al Gobierno socialista de José Luis Rodríguez Zapatero, que se encontraba entonces en su segundo mandato, sino que hubo de facilitar la puesta en vigor del resto de las importantes reformas institucionales y materiales que el Tratado trajo consigo.

85 Intervención del Ministro Moratinos en la tramitación directa y en lectura única del proyecto de Ley Orgánica por la que se autoriza la ratificación por España del Tratado de Lisboa. (Diario de Sesiones del Congreso de los Diputados, Año 2008, IX Legislatura, Núm. 14, Sesión plenaria núm. 14, martes 10 de junio de 2008; p. 44).

86 Véase el detalle de este proceso de ratificación en BAR CEndón, Antonio, «El Tratado de Lisboa y la reforma constitucional de la Unión Europea», Cuadernos Constitucionales de la Cátedra Fadrique Furió Ceriol, n. ${ }^{\circ}$ 60/61 (2007) (de facto 2009), pp. 183-220; Bar Cendón, Antonio, «De Niza a Lisboa: El Tratado de Lisboa y la Carta de los Derechos Fundamentales de la UE», en A. Bar Cendón, Los Tratados de la Unión Europea. Edición anotada realizada por Antonio BAR CEndón (Valencia: Tirant lo Blanch, 2010); BAR CEndón, Antonio, «La nueva Constitución de la Unión Europea: El Tratado de Lisboa y la reforma de los Tratados constitutivos», Teoría y Realidad Constitucional, 25 (2010), pp. 167210. (ISSN: 1139-5583).

${ }^{87}$ Consejo de Estado, Dictamen sobre el Tratado de Lisboa (24/2008), de 13 de marzo de 2008. En: https://www.boe.es/legislacion/consejo_estado.php?campo $\% 5 \mathrm{~B} 0 \% 5 \mathrm{D}=$ doc\&dato\%5B0\%5D=Tratado + de + Lisboa + \&operador $\% 5 \mathrm{~B} 0 \% 5 \mathrm{D}$

${ }^{88}$ Ley Orgánica 1/2008, de 30 de julio, por la que se autoriza la ratificación por España del Tratado de Lisboa (BOE núm. 184, 31 julio 2008). 


\section{CONCLUSIONES}

Para España, el proceso de integración europeo ha supuesto un objetivo ideológico y un proyecto político. Como objetivo ideológico el proceso europeo de integración ha sido - es - compartido por la práctica totalidad de los partidos políticos mayoritarios, que lo han asumido en sus programas, incluso como una etiqueta distintiva de identificación: ser partido europeo, o europeísta. Este punto de partida ideológico ha venido a facilitar mucho la integración de España en las CCEE, primero, y en la UE después, y a permitir el pleno aprovechamiento de los recursos europeos y de la posición de España en el seno de la Unión, tanto en relación con los demás Estados miembros, como en el conjunto de las relaciones internacionales. Pero, sobre todo, ha permitido a España también volcarse en la realización de un proyecto de integración política plenamente asumido y que es conforme con el conjunto de los valores y objetivos últimos diseñados por los padres fundadores de la Unión.

Y, como proyecto político, no cabe duda alguna de que España ha participado también de manera intensa en el diseño del gobierno de la Unión que se deriva de los tratados aprobados tras su ingreso, en 1986. Tratados en los que intentó aportar su particular visión del proceso y, desde luego, en los que, en la medida de lo posible, trató también de asegurar la protección de sus propios intereses. Es verdad, sin embargo, que la posición de España no ha tenido siempre la misma fuerza y que su solidez no ha dependido sólo del carácter de sus planteamientos, sino también del liderazgo político y de la influencia de sus presidentes del Gobierno. En este sentido, es evidente que los liderazgos de Felipe González y de José María Aznar han sido mucho más fuertes, y ello se ha manifestado en la similarmente potente posición de España en la UE bajo su mandato. Así se ha visto principalmente en los debates sobre el Acta Única Europa, el Tratado de Maastricht y el Tratado de Ámsterdam, en el caso del Presidente González, y sobre el Tratado de Niza y la Constitución europea, en el caso del Presidente Aznar. No ocurrió lo mismo, en cambio — como se ha visto—-, en el debate sobre el Tratado de Lisboa, en el caso del Presidente Zapatero.

La posición de España, en todo caso, ha sido notablemente coherente y lineal en sus planteamientos, en términos generales, con respecto a los aspectos sustantivos de la UE; y aquí no ha habido grandes diferencias entre los diversos gobiernos españoles del momento. Así, España se ha manifestado siempre favorable a la profundización en el proceso de integración política de Europa y, desde luego, también con respecto al proceso de integración económica. España se ha manifestado siempre favorable a la conformación de una sólida política exterior y de seguridad común de la UE, y también a la definición de una política común de defensa. España siempre ha defendido la existencia de una activa política social y de cohesión y, por lo tanto, de atención especial al desempleo y a las regiones más desfavorecidas de la Unión. España ha luchado por el reconocimiento y protección de los derechos fundamentales en el ámbito europeo y por la consolidación del concepto de ciudadanía europea. España ha promovido siempre la cooperación judicial y policial, y la lucha contra el terrorismo, incluso 
cuando algunos Estados europeos no parecían dar relevancia a esta cuestión. Y, en fin, España se ha manifestado siempre favorable al proceso de ampliación de la UE a nuevos Estados, aunque ello, en los últimos años, haya supuesto una disminución drástica de las contribuciones económicas recibidas de la Unión, debido también, en buena medida — y esto ha de ser subrayado—-, al propio desarrollo económico conseguido tras el ingreso en las CCEE. La integración de España en el marco de lo que es hoy la UE, pues, ha supuesto para España una importante contribución a su desarrollo económico, social y político, pero ha supuesto también para la UE una aportación muy positiva al progreso del proyecto europeo de integración que ésta encarna.

$$
* * *
$$

Title:

Spain and the EU: Ideological objective and political project (1978-2018)

\section{Summary:}

1. Introduction. 2. Europe as an ideological objective. 3. Europe as a political project. A) The first step: The Single European Act. B) Citizenship and cohesion: The Treaty of Maastricht. C) The foreign role and the social policy: The Treaty of Amsterdam. D) Enhancing the institutional position: The Treaty of Nice. E) From toughness to concession: The European Constitution. F) Weakness and relocation: The Treaty of Lisbon. 4. Conclusion.

\section{Resumen:}

El reingreso en el contexto europeo, del que España fue expulsada tras el final de la Segunda Guerra Mundial, ha sido durante largo tiempo el objeto del componente ideológico y del proyecto político de la práctica totalidad de las fuerzas políticas españolas. El ingreso de España en las Comunidades Europeas, en enero de 1986, vino a suponer la realización de ese objetivo ideológico y de ese proyecto político. Desde entonces, España experimentó importantes cambios que mejoraron notablemente su estructura económica, pero también otros aspectos políticos y sociales. Estos cambios han sido descritos y analizados por la doctrina científica con todo detalle y extensión. Este trabajo, sin embargo, trata de describir y analizar cuáles han sido las aportaciones de España al proceso de integra- 
ción europeo y su desarrollo en cada fase del mismo, y lo hace partiendo precisamente de lo que fueron los planteamientos políticos e ideológicos de las principales fuerzas políticas del momento. Algo que no se ha hecho hasta el presente con la debida extensión e interés que merece el tema.

\section{Abstract:}

The return to the European context, from which Spain was expelled after the end of the Second World War, has been the object of the ideological component and of the political project of almost all of the Spanish political forces for a long time. The admission of Spain into the European Communities, in January 1986, meant the realization of that ideological objective and political project. Since then, Spain experienced important changes that significantly improved its economic structure, but also other political and social aspects. All of these changes have been extensively described and analyzed by the specialized literature. This paper, however, tries to describe and analyze Spain's contributions to the European integration process at each phase of its development, and it does so departing precisely from a description of the political and ideological positions of the political forces of that period. This is something that has not been done so far, with the extension and interest that the subject deserves.

\section{Palabras clave:}

Comunidades Europeas, Unión Europea, proceso de integración, partidos políticos, Tratados

Key words:

European Communities, European Union, process of integration, political parties, Treaties. 